\title{
Parameter Analysis of Thermoelectric Generator/dc-dc Converter System with Maximum Power Point Tracking
}

Ssennoga Twaha, Jie Zhu*, Bo Li, Yuying Yan, Kuo Huang

Fluids \& Thermal Engineering Research Group, Faculty of Engineering, University of Nottingham, NG7 2RD, United Kingdom

\begin{abstract}
:
The power generated from TEG is relatively unstable owing to temperature variations at its hot and cold side terminals. The dc-dc converters can provide more stable power output thereby improving the overall efficiency of TEG system. However, to facilitate better performance improvement, maximum power point tracking (MPPT) algorithm can be applied to extract maximum power from TEG system. Therefore, parameter analysis of a TEG/dc-dc converter system in different modes is being carried out. A TEG-dc-dc boost converter model is analysed in both MPPT and direct pulse width modulation (PWM) modes subjected to a variable load. To further study the capability of dc-dc converters to stabilise the TEG power output, increasing ramp and random hot side temperature is applied to the MPPT and direct PWM based modes so that the effect on output parameters i.e. voltage and power, can be analysed. It is noted that even for the random temperature input to the TEG, the output voltage resulting from the converter is almost constant. Therefore dc-dc converters are able to stabilise the power generated from TEG. It is also observed that dc-dc converter with MPPT based model is able to effectively extract the maximum power without having to adjust any component from the MPPT algorithm as it is the case with direct PWM based model. From the study, it has been established that proper selection of converter components is necessary to reduce converter losses as well interferences on the load connected to TEG-dc-dc converter system.
\end{abstract}

Keywords: TEG devices; random temperature; dc-dc converter; MPPT; direct PWM.

*Corresponding author: Jie Zhu: Email: lazjz@ nottingham.ac.uk. Tel. +44 1158466141. 


\section{Introduction}

Energy-harvesting systems which convert heat into electricity with the use of thermoelectric energy generation (TEG) devices are being constantly developed and manufactured [1][2]. A number of currently available and applicable low-grade waste heat recovery methods adopt thermoelectric (TE) modules including plant/district/water heating, direct power generation and others [3]. TE modules offer low cost electricity without moving parts or production of environmentally deleterious wastes [4]. However, the optimal performance of TE modules depends on several factors like material properties and operation strategy [5].

Various research efforts are underway to improve the performance of TE conversion system. The integrated thermoelectric devices are also developed by restructuring them to allow more heat to enter the $\mathrm{p}-\mathrm{n}$ junctions, thereby producing more power output [6]. Product development for TEG devices requires solving a couple of challenges in material and system construction aspects for numerous TEG system applications [7]. Accuracy of mathematical models used in thermoelectric simulation is assessed with special reference to thermal influence of insulated air zone and radiation heat [8]. Heat transfer analysis between TEG cold and hot plates reveals that the developed model is of theoretical significance in guiding TEG design for high-power or large-temperature-difference application. Different TEG structures including rotated and coaxial leg configurations [9], rectangular prism and cylindrical legs [10], have been evaluated with regards to power output, temperature distribution, conversion efficiency and thermal stresses in the legs. Not forgetting to mention the concentric cylindrical design which is also applied to TEG system with improved power output [11]. With all these efforts, it is still necessary to do more research work on the performance improvement for TEG systems.

Maximum power point tracking (MPPT) methods for a long time have been applied to improve the performance of photovoltaic (PV) system in both normal and partial shading conditions [12]. In order to fully utilize the energy generated from TEG systems, dc-dc converters with MPPT are being adopted to stabilize the output voltage generated from TEG as well as to ensure maximum power extraction from TEG system [13][14][15][16] [17][18]. In [13], an analysis is carried out on an MPPT control strategy for thermoelectric-solar hybrid energy harvesting system. The hot side temperature is set between $40^{\circ} \mathrm{C}$ and $50^{\circ} \mathrm{C}$ while single supercapacitor is used as the load to the system purposely to increase the tracking response. The authors in [14] presented a simple MPPT method for TEG which is based on controlling a power converter such that it operates on a pre-programmed locus of operating points close to the MPPs of the power-voltage curves. In their work, a single battery is used as the load. In 
60

61

62

63

64

65

66

67

68

69

70

71

72

73

74

75

76

77

78

79

80

81

82

83

84

85

86

[16], Yi-Hua et al. presented a novel MPPT for TEG system which combines the benefits of perturb and observe $(\mathrm{P} \& \mathrm{O})$ method and the fast tracking ability of open circuit voltage (OCV) method with batteries used as the load to the system. In reality, temperature profiles are random in nature, especially in vehicles. As well, some loads are never constant, making it a necessity to analysis the TEG-converter systems when they are subjected to different loads. In our previous study [19], an IC-based MPPT method is presented with a ramp step temperature on the hot side and a constant temperature on the cold side whereas the converter is subjected to a constant resistive load. Therefore, it is necessary to test the TEG-converter system with a random temperature because temperature profiles are random in most of the real applications. Moreover, it is necessary to analyse the system with a variable load to identify the optimal load for the TEG-converter system to perform near its maximum potential. The objective of this work is to investigate the parameters of TEG-dc-dc converter system enabled by incremental conductance (IC) based MPPT and direct PWM signals. The converter performance is analysed with reference to the temperature variation at the hot side of TEG in addition to varying the external converter load. The study is aimed to test the TEG output power conditioning model for application in the waste heat recovery in low carbon vehicle.

\section{Thermoelectric module}

A Single p-n pair of the TEG module is shown in Fig. 1. A TEG is a solid-state device that can convert heat directly into electrical energy when a temperature difference is placed across it [20]. Electric power can be converted to cooling or heating by reversing the current direction [21]. In a thermoelectric material there are free electrons or holes which carry both charge and heat. The electric potential (Voltage) produced by a temperature difference is known as the Seebeck effect and the proportionality constant is called the Seebeck coefficient. If the free charges are positive (the material is p-type), positive charge will build up on the cold end which will have a positive potential. Similarly, negative free charges (n-type material) will produce a negative potential at the cold end. 


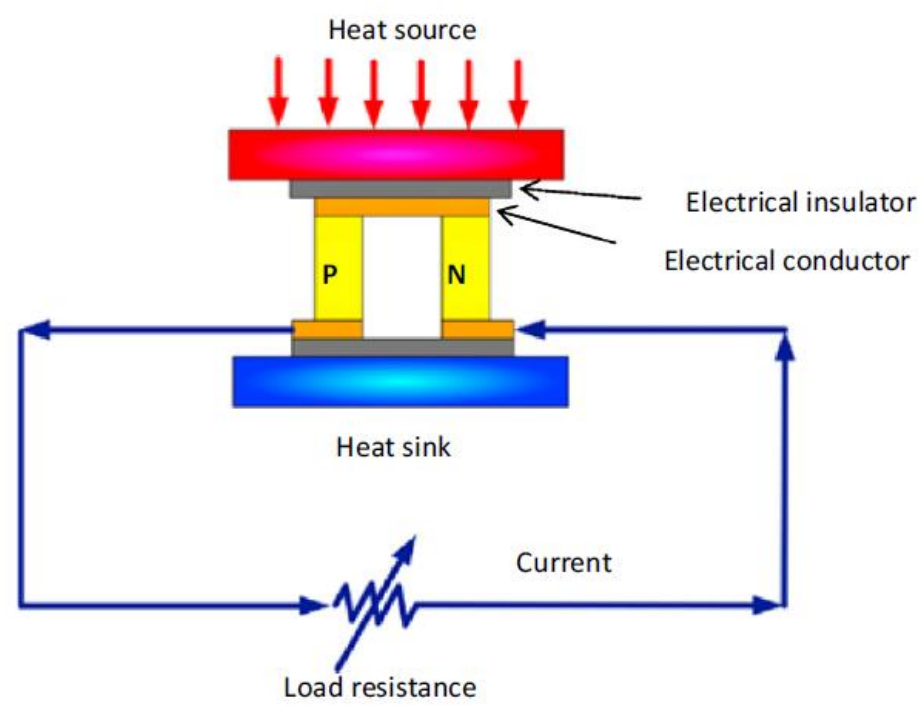

Fig. 1. A Single p-n pair of the TEG module [22].

While choosing TEGs for application in varying conditions, it is necessary to select an appropriate semiconductor with acceptable performance in the temperature range of that condition [23]. The figure of merit $(\mathrm{Z})$ is a parameter generally used to gauge the performance of a TE material:

$$
Z=\frac{S_{p, n}^{2} \sigma_{p, n}}{\lambda_{p, n}}
$$

Where $S_{p, n}$ is the Seebeck coefficient of n-type or p-type material; $\sigma_{p, n}$ is the electrical conductivity of the material in p-type or n-type in Siemens per meter whereas $\lambda_{p, n}$ is the thermal conductivity [23]. All these parameters are known and sometimes given in the datasheet from the manufacturers of the TE devices.

In general, for obtaining maximum efficiency, the important characteristic for thermoelectric material is the dimensionless measurement thermoelectric performance figure of merit ZT [21].

$$
Z T=\frac{\sigma S^{2} T}{\lambda}
$$

Where $\mathrm{S}, \sigma, \mathrm{T}$ and $\lambda$ are the Seebeck coefficient, electrical conductivity, absolute temperature and thermal conductivity, respectively. In order to get high thermoelectric efficiency, the figure of merit should be large i.e. ZT>1. Alloys, particularly with AgSbTe2, have led to several reports of ZT>1 for both n-type and p-type materials. The p-type alloy (GeTe) 0.85(AgSbTe2)0.15, having maximum ZT>1.2, is successfully used in durable TEGs [24]. 


\section{TEG-dc-dc converter model}

108

The developed model is shown in Fig. 2 consisting of the TEG, dc-dc converter and the MPPT algorithm as discussed in the following subsections.

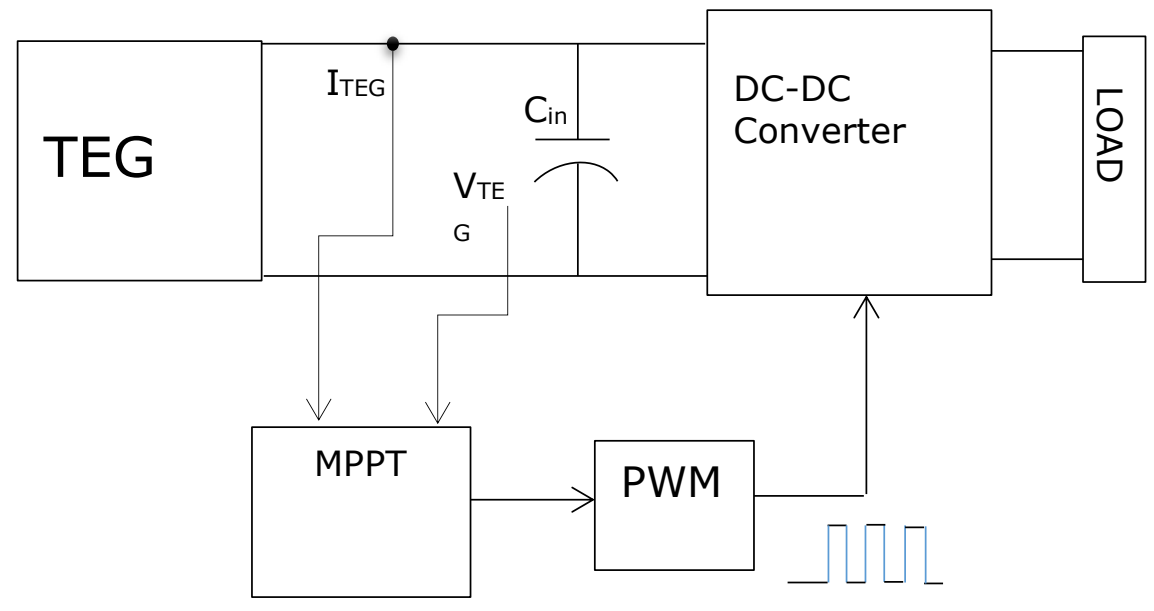

Fig. 2. The TEG-converter simulation model

\subsection{TEG Model}

TEG is modelled based on the concept of simplified model in which some thermoelectric effects are ignored [5]. This is done for simplicity although there is reduced accuracy. The following equations are used to design the model

$$
\begin{aligned}
& \text { Seebeck coefficient }(S)=\frac{2 V_{\text {match }}}{\Delta T_{s p}} \\
& \text { temperrature difference }(\Delta T)=T_{h}-T_{c}
\end{aligned}
$$

For TEG made of two semiconductor components, the output voltage of TEG is expressed as $[25]$

$$
V_{o c}=\left(\alpha_{p}-\alpha_{n}\right)(\Delta T)\left(N_{T E G-s}\right)
$$

For TEG made of a single semiconductor type, $V_{o c}$ is given as;

$$
V_{o c}=\left(N_{T E G-S}\right)(\Delta T)(S)
$$

$$
R_{\text {int }}=m\left[\frac{T_{h}+T_{c}}{2}\right]+n
$$


Where $\alpha_{p}$ and $\alpha_{n}$ are the Seebeck coefficients of the $\mathrm{p}$ - and n-type materials of TEG

127 respectively; $\mathrm{S}$ is the Seebeck coefficients of a single material for TEG; $\mathrm{V}_{\text {match }}$ is the matched

128 load voltage, $\Delta T_{s p}$ is the temperature difference of the measurement stated in TEG datasheet,

$129 T_{h}$ and $T_{c}$ are the hot and cold side temperatures of TEG respectively; $\mathrm{N}_{\text {TEG-s }}$ is the number of

130 TEG modules, $\mathrm{R}_{\text {int }}$ is the TEG internal resistance, $m$ is the TEG internal resistance vs TEG temperature $\left(\mathrm{R}_{\text {int }}-\mathrm{T}\right)$ curve slope and $n$ is the $\mathrm{R}_{\text {int }}-\mathrm{T}$ curve intercept;

The TEG model internal resistance $R_{\text {int }}$ and the open circuit voltage $V_{o c}$ vary in real time with temperature. The real-time values of $\mathrm{V}_{\text {oc }}$ and $\mathrm{R}_{\text {int }}$ are mapped to the controlled voltage source and variable resistance respectively in the converter to generate its input voltage and current [26]. The model is designed with time-varying hot side temperature and a constant cold side temperature. It is masked to input other parameters included in the datasheets of practical TEG module from different manufacturer including $\mathrm{V}_{\text {match }}, \mathrm{N}_{\text {TEG-s}}, \Delta \mathrm{Tsp}, m$ and $n$. So the results of the model can be compared with the practical results of manufactured TEGs if experiments are carried out. The TEG1-12611-6.0 module parameters which is used in [27] are applied in this work with its specification shown in Table I.

Table I. Specifications of the TEG module

\begin{tabular}{|l|l|}
\hline Hot side temperature $\left({ }^{\circ} \mathrm{C}\right)$ & 300 \\
\hline Cold side temperature $\left({ }^{\circ} \mathrm{C}\right)$ & 30 \\
\hline Matched load output voltage $(\mathrm{V})$ & 4.2 \\
\hline Matched load output current $(\mathrm{A})$ & 3.4 \\
\hline Matched load resistance $(\mathrm{Ohms})$ & 1.2 \\
\hline Matched load output $(\mathrm{W})$ & 14.6 \\
\hline Open circuit voltage $(\mathrm{V})$ & 8.4 \\
\hline Heat flow across the module $(\mathrm{W})$ & Approximately 365 \\
\hline Heat flow density $\left(\mathrm{Wcm}^{-2}\right)$ & Approximately 11.6 \\
\hline AC Resistance measured at $27^{\circ} \mathrm{C}$ at $1000 \mathrm{~Hz}(\Omega)$ & $0.5-0.7$ \\
\hline
\end{tabular}

\subsection{The dc-dc boost converter model}

Here the converter that operates in a continuous conduction mode (CCM) is discussed with regard to the design specifications and components selection. The first step in designing a dc$\mathrm{dc}$ boost converter is to find the appropriate value of switching current which is the maximum 
current the switch or integrated circuit (IC) the inductor and the diode can withstand. But before that, the duty cycle $\mathrm{D}$ and the ripple current have to be determined. The duty cycle of a practical dc-dc boost converter is expressed as;

$$
D=\frac{V_{\text {in }(\min ) * \eta_{\text {conv }}}}{V_{\text {out }}}
$$

Where $V_{\text {in (min) }}$ is the minimum input voltage; $\eta_{\text {conv }}$ the converter efficiency whereas $V_{\text {out }}$ is the desired output voltage.

The efficiency is included in the duty cycle equation in order to compute a more realistic value of $\mathrm{D}$ in addition to catering for the dissipated energy since the converter has the energy losses. Either an estimated efficiency value can be used e.g. $82 \%$ or a typical efficiency value can be selected from the converter characteristics from the datasheet for use in equation (8).

Before calculating the ripple current, it is necessary to first compute or determine the inductor value. Various ways are used to determine the inductor value; the recommended inductor value or the middle value in the inductor range given in the datasheet can be used if there is no recommended value given. Alternatively, the inductor value can be computed as;

$$
L=\frac{V_{\text {in }} *\left\{V_{\text {out }}-V_{\text {in }}\right\}}{\Delta I_{L} * f_{\text {sw }} * V_{\text {out }}}
$$

Where $V_{\text {in }}$ is the typical input voltage; $f_{s w}$ the minimum converter switching frequency while $\Delta I_{L}$ is the estimated inductor ripple current.

A suitable value of $f_{s w}$ for the converter application without causing losses should be selected. The inductor ripple current is not calculated but estimated in the range of $20 \%-40 \%$ of the output current as;

$$
\Delta I_{L}=0.2 * I_{\text {out_max }} * \frac{V_{\text {in }}}{V_{\text {out }}}
$$

Where $I_{\text {out_max }}$ is the maximum output current for designated converter load.

Therefore, the ripple current is expressed as;

$$
\Delta I_{L}=\frac{V_{\text {in_min }} * D}{f_{S w^{* L}}}
$$

The ripple current should be reduced in the converter circuit because if it is left to penetrate the converter load such as the battery, it can reduce battery life and degrade the operation of the load [28]. Switching ripple filters can be used to prevent the switching ripple current from reaching the load or grid [29].

The maximum output current delivered by the converter is calculated as

$$
I_{\text {out_max }}=\left[I_{I C_{-} \min }-\frac{\Delta I_{L}}{2}\right] *(1-D)
$$

Where $I_{I C \_ \text {min }}$ is the minimum value of current for the IC given in datasheet. 
Another IC of higher switching current has to be selected if $I_{\text {out_max }}$ of the selected IC is below the targeted maximum current value of the application or the load. However, if $I_{\text {out }}$ max is slightly smaller than the required maximum load current, the inductor value can be increased as longer as the increased inductance remains within the recommended range in the datasheet. This is because increasing inductance reduces the ripple, thereby increasing the maximum output current to the desired value. If calculated $I_{\text {out_max }}$ is above the required maximum output current, then the switching current $I_{S w_{-} \max }$ is calculated as:

$$
I_{S w_{-} \max }=\left[\frac{\Delta I_{L}}{2}+\frac{I_{\text {out_max }}}{1-D}\right]
$$

To select the diode, the average forward current rating required is equal to $I_{\text {out_max }}$ i.e.

$$
I_{F}=I_{\text {out_max }}
$$

Where $I_{F}$ is the diode's average forward current.

For reduced losses, Schottky diode types should be utilized. They also have higher peak current than their rating and the higher peak current is not a problem. The power dissipated by the diode is:

$$
P_{F}=I_{F} * V_{F}
$$

Where $V_{F}$ is diode's Forward voltage.

The practical diodes have different threshold forward voltages (barrier potential) $\mathrm{V}_{\mathrm{o}}$ beyond which the diode is able to conduct large amount of current to the output terminal of the converter. The value of $\mathrm{V}_{\mathrm{o}}$ is normally $0.2 \mathrm{~V}, 0.3 \mathrm{~V}$ and $0.7 \mathrm{~V}$ for Shockley, germanium and silicon diodes respectively. A practical or real diode has a barrier potential $\mathrm{V}_{\mathrm{o}}$ and a drop-in forward resistance $\mathrm{R}_{\mathrm{F}}$. Therefore the required voltage $\mathrm{V}_{\mathrm{F}}$ to operate the diode in forward biased mode becomes:

$$
V_{F}=V_{0}+R_{F} I_{F}
$$

Where $I_{F}$ is the forward current.

The next step is to select the capacitance. Due to peak current requirement of the converter the input voltage has to be stabilized by a minimum value of input capacitor. The minimum value of input capacitor $\mathrm{C}_{\text {in }}$ is always specified in the datasheet. Ceramic capacitors are recommended because they have low Equivalent Series resistance (ESR). The capacitance $C_{\text {in }}$ can be increased if the input voltage has higher noise so that higher harmonics are suppressed to avoid noise interference. Class 2 ceramic capacitors with dielectric material X7R should be used for higher temperature applications because they operate in the temperature range of $55{ }^{\circ} \mathrm{C}$ to $+150{ }^{\circ} \mathrm{C}$ with a capacitance change $\Delta \mathrm{C} / \mathrm{C} 0$ of utmost $\pm 15 \%$. The X5R capacitors show 
211 a capacitance drift that may not exceed $15 \%$ of the nominal capacitance value at $25{ }^{\circ} \mathrm{C}$ in a 212 temperature range from -55 to $85{ }^{\circ} \mathrm{C}$ [30]. If lower temperature rated capacitors are used, the 213 capacitor would lose much of its capacitance due to temperature or DC bias.

214 During selection of output capacitor $\mathrm{C}_{\text {out }}$, low ESR should be put into consideration to 215 reduce the ripple on the output voltage. Capacitors with similar qualities as $\mathrm{C}_{\text {in }}$ can be used as 216 Cout.

217 The recommended $\mathrm{L}$ and $\mathrm{C}$ values in the datasheet should be used if internal compensation 218 is used in the converter. If external compensation is used, the capacitance has to be adjusted 219 as:

$$
C_{\text {out_min }}=\frac{I_{\text {out_max }} * D}{f_{S w^{*} \Delta V_{\text {out }}}}
$$

221 Where $C_{\text {out_min }}$ is the minimum value of output capacitance; $\Delta V_{\text {out }}$ is the desired output 222 voltage ripple.

223 The additional ripple caused by ESR of $C_{\text {out }}$ is expressed as:

$$
\Delta V_{\text {out_ESR }}=\left[\frac{\Delta I_{L}}{2}+\frac{I_{\text {out_max }}}{1-D}\right] * E S R
$$

\subsection{Incremental conductance algorithm}

227

The IC method operates by incrementally comparing the ratio of derivative of conductance with the instantaneous conductance. This is due to the fact that at maximum power point 230 (MPP), the derivative of power with respect to voltage $(d P / d V)$ is zero, i.e.

$$
\frac{d P}{d V}=\frac{d(V I)}{d V}=I+V \frac{d I}{d V}=0
$$

232 After re-arranging Eq. (15)

$$
-\frac{I}{V}=\frac{d I}{d V} \cong \frac{\Delta I}{\Delta V}
$$

Where $\mathrm{I}$ and $\mathrm{V}$ are the TEG output current and voltage; $\Delta \mathrm{I}$ and $\Delta \mathrm{V}$ are the increments of TEG output current and voltage, respectively. The basic rules for IC can be written as:

$$
\left\{\begin{array}{lr}
d I / d V=-I / V, & \text { At MPP } \\
d I / d V>-I / V, & \text { Left of MPP } \\
d I / d V<-I / V, & \text { Right of MPP }
\end{array}\right.
$$


239 It can be noticed that the MPP condition $(d I / d V+I / V=0)$ rarely exists in practical 240 applications; hence another alternative yet effective way to utilize the IC was proposed by a 241 number of researchers [17]. The idea is to generate a marginal error $\mathcal{E}$ using the instantaneous 242 conductance and the incremental conductance. Mathematically, it can be written as:

$$
d I / d V+I / V=\varepsilon
$$

244 From Eq. (22), it can be seen that the value of $\varepsilon$ is zero at MPP. Hence, based on the amount 245 of $\varepsilon$ and using the rules of Eq. (21), the basic flow chart for IC method is shown in Fig. 3. 


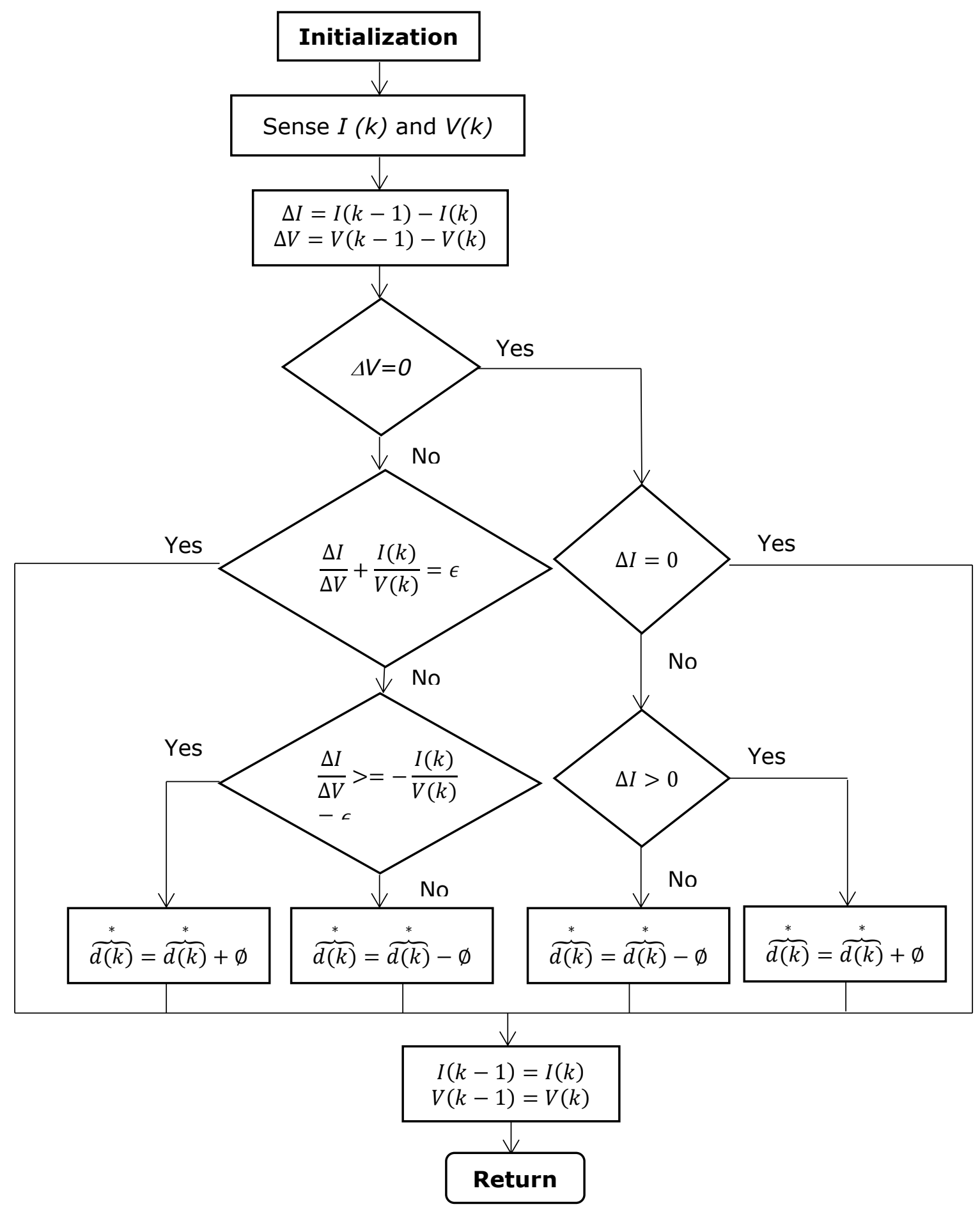

Fig. 3. Basic flow chart of incremental conductance (IC) method [31]

4. Results and discussion

The TEG-dc-dc converter model is tested with input temperature in the range of $150^{\circ} \mathrm{C}$ to $250^{\circ} \mathrm{C}$. As indicated in the introduction, the aim of this work is to test the TEG output power conditioning model used in the waste heat recovery in low carbon vehicles. Therefore, the 
chosen maximum temperature is based on the fact that in the gas oil or hybrid vehicles, the average temperature of the exhaust manifold is over $250^{\circ} \mathrm{C}$ [32]. The input temperature test scenarios for the model are shown in Fig. $4 \mathrm{a}$ and $4 \mathrm{~b}$ for an increasing step and random signals respectively at hot side temperature terminal.

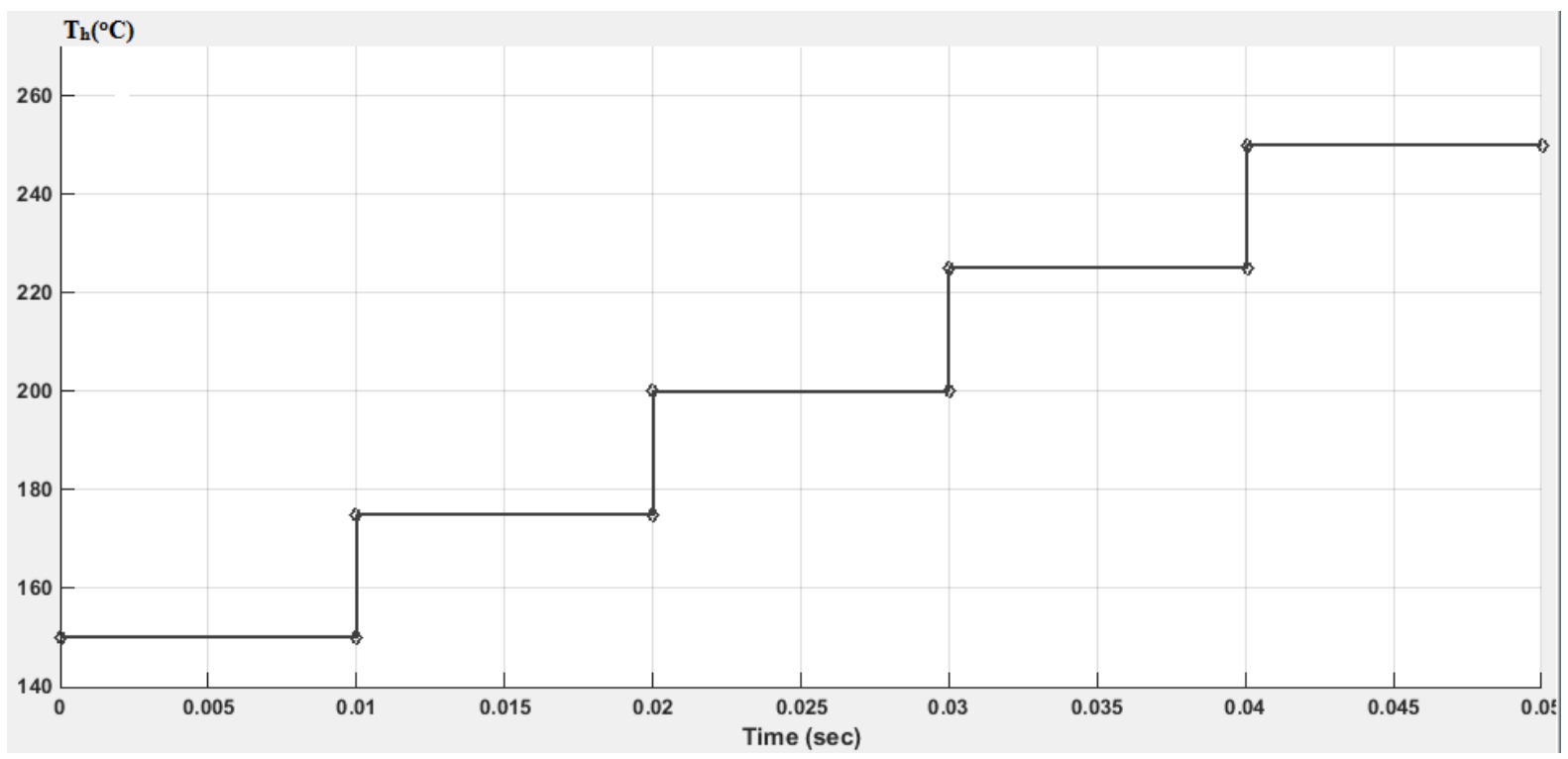

Fig. 4a. Increasing step hot side temperature

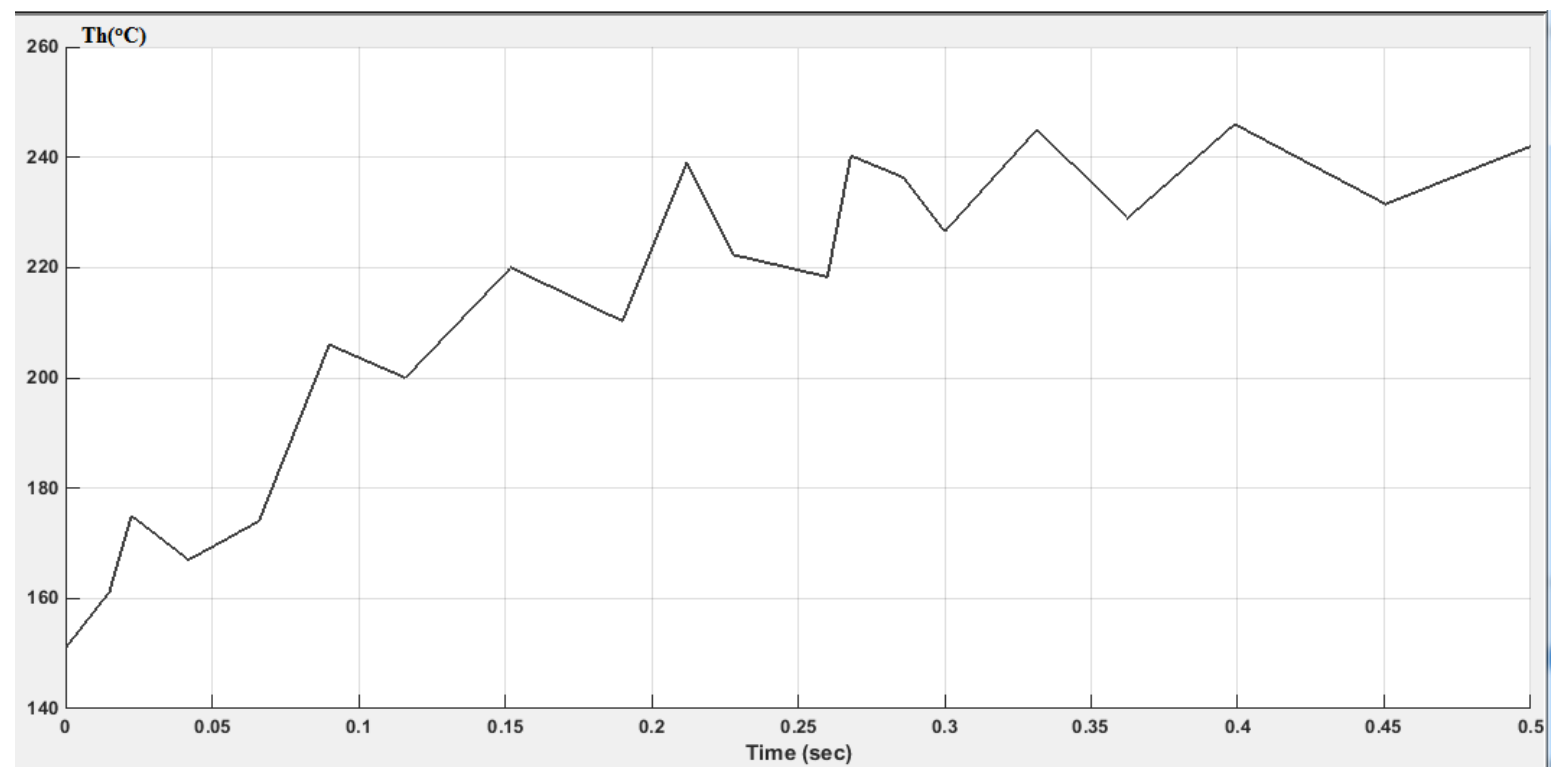

Fig. 4b. Increasing random hot side temperature

\subsection{Results for the increasing step hot side temperature}

The results in this section are based on the temperature input of an increasing step signal at the hot side temperature terminal of the model whereas at the cold side terminal, the 
temperature is maintained at a constant value of $30^{\circ} \mathrm{C}$. The model has been operated in both MPPT and direct PWM switching modes to compare their performances.

\subsubsection{Converter parameters with the MPPT mode}

271

During the MPPT mode the model is subjected to varying loads in the range of $0-14 \Omega$ in order to find out the effect of different loads on the converter parameters including output voltage, current and power. Fig. 5 and 6 show the input and output voltages of the converter at different temperatures. It can be observed from both figures that the input as well as the output voltage increases with the temperature. So the highest voltage is observed at hot side temperature $\left(T_{h}\right)$ of $25^{\circ} \mathrm{C}$. This is because as $T_{h}$ increases under a constant cold side temperature $T_{c}$, the temperature difference at TEG increases and in turn the Seebeck effect which is responsible for the generated voltage increases.

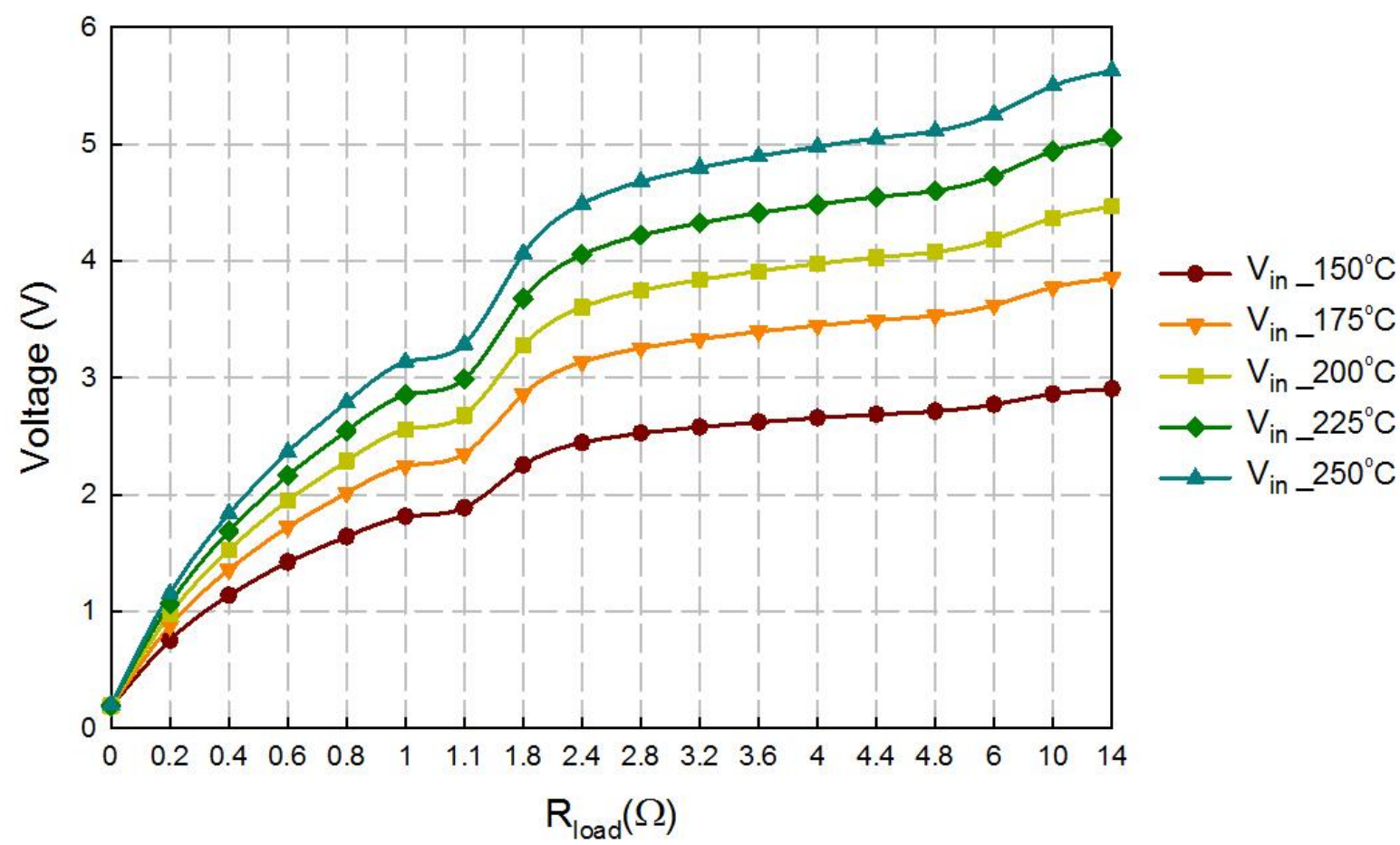

Fig. 5. Variation of input voltage of the converter with load resistance 


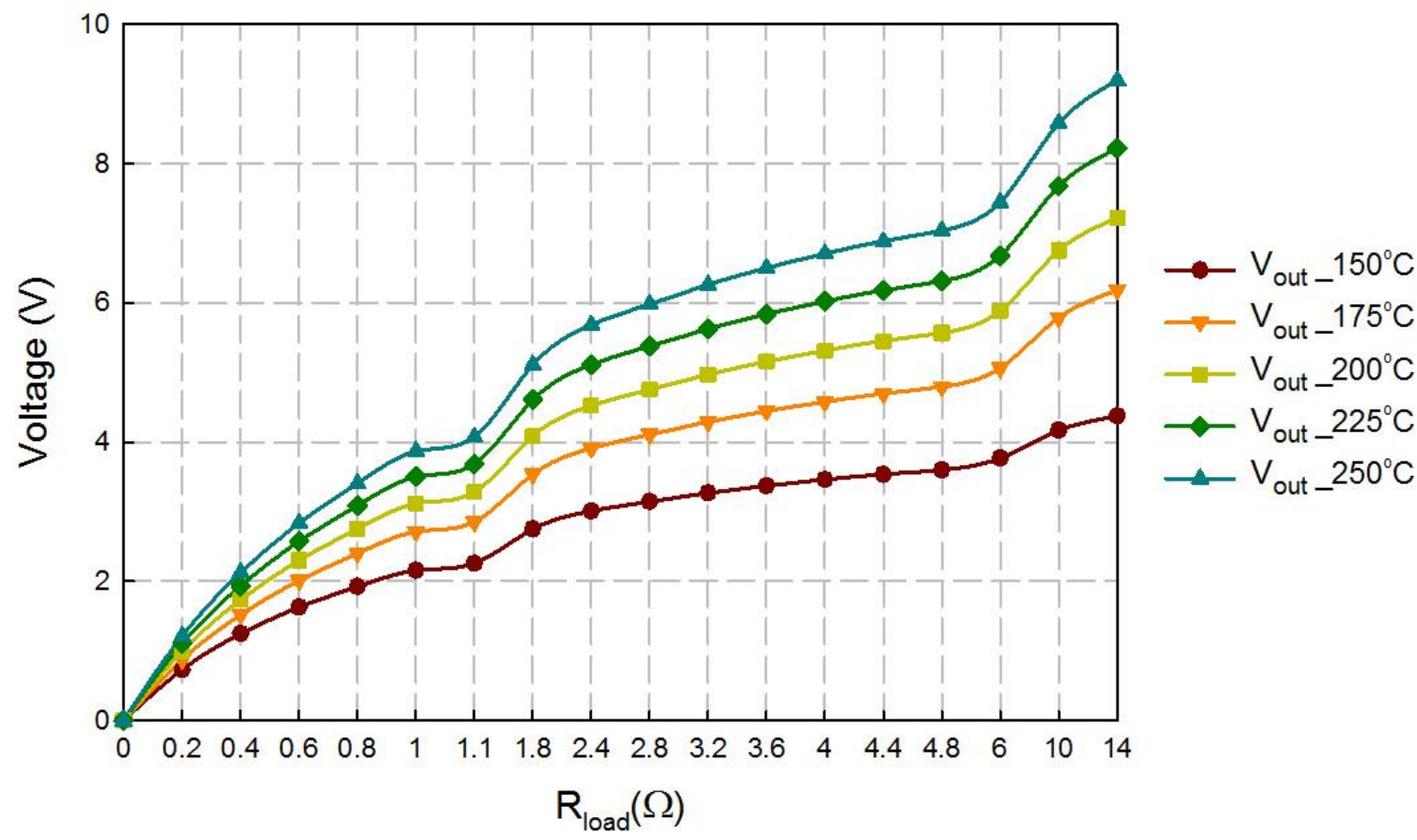

Fig. 6. Variation of output voltage of the converter with load resistance

It is also clear that as the converter load increases, the input and output voltages also rise. However, a sharp increase in the voltage is observed from zero resistance up to $1.1 \Omega$ where the rate of rise reduces. The rate of voltage rise again increases after $\mathrm{R}_{\text {load }}$ of $1.1 \Omega$ onwards until at the about $10 \Omega$. The interpretation for this trend is better explained based on power curve for TEG shown in Fig. 7. The graph of $\mathrm{R}_{\text {load }}$ against power output of the converter indicates that at a converter load of $1.1 \Omega$, this is where the maximum power is obtained from the converter. This load is referred to as the optimal load at which the total resistance of the converter (including the ESR and other parasitic resistance of the components) is equal to the internal resistance of the TEG, $R_{\text {int }}$. At this point, the load is said to be matched and it is advisable to operate the converter at this load to harvest maximum power from the TEG-dc-dc converter system. The increase in $T_{h}$ results in the corresponding increase in internal resistance of TEG device leading to the rise in the optimum points due to increase in the value of matching load resistance as seen in Fig. 7. Given the nature of the variation of the internal resistance of TEG, it is very hard to archive the load matching point, hence the use of MPPT algorithm. 


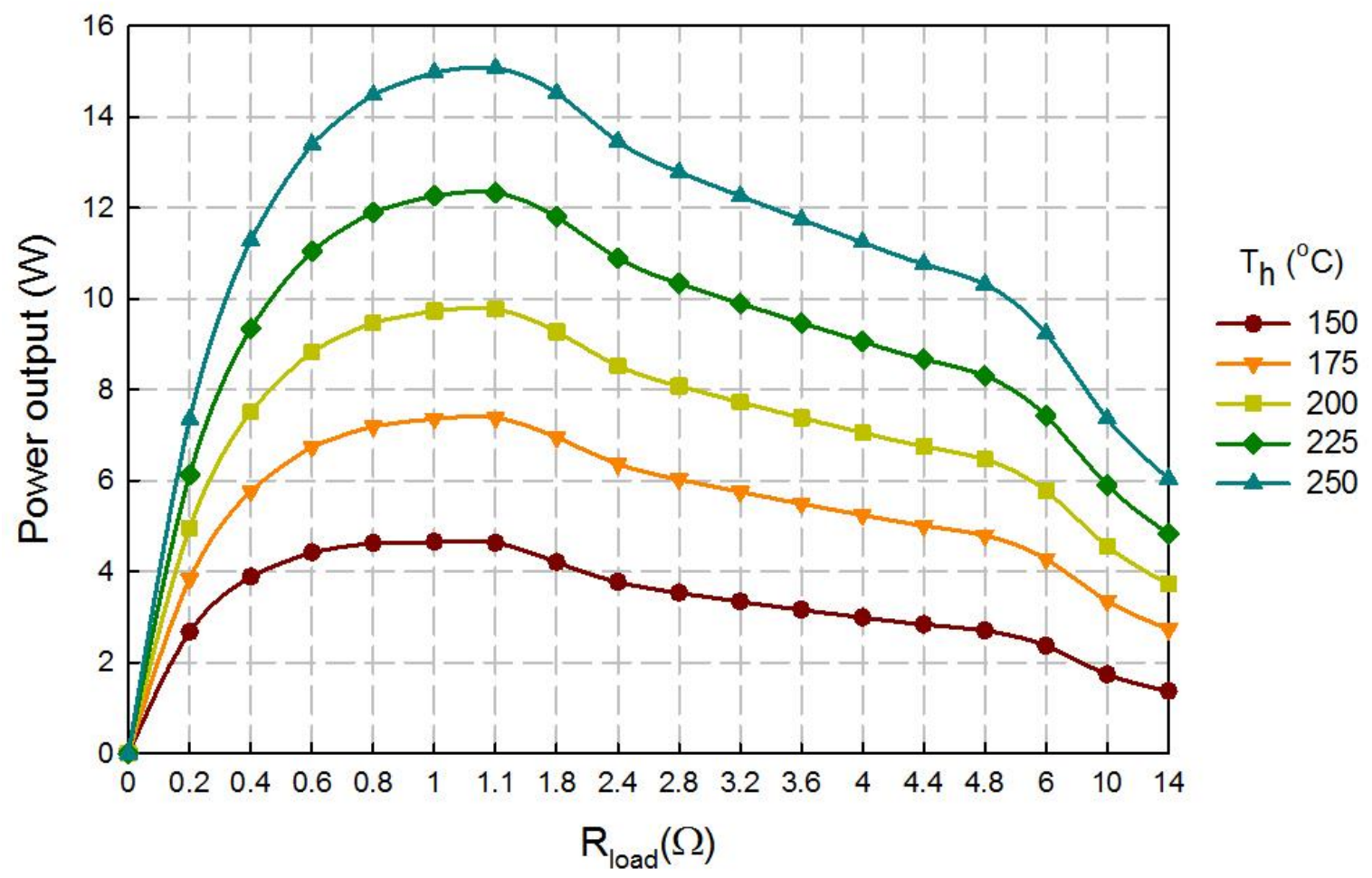

Fig. 7. Variation of output power with converter with load resistance

Fig. 8 shows the I-V characteristic of the converter plotted with output power. It is seen that as the converter load is increased, the output current reduces but the output voltage instead increases. The current and voltage curves meet almost at the maximum power point i.e. at the load matching point though the point of intersection is not the same for different hot side temperature. The output current is maximum at zero load. In ideal circuit, the current is always zero at zero load but in this case the current is maximum since there is some ESR resistance in the output capacitor which is parallel to the output terminal. So, the current through the diode takes the easiest path to the ground. 


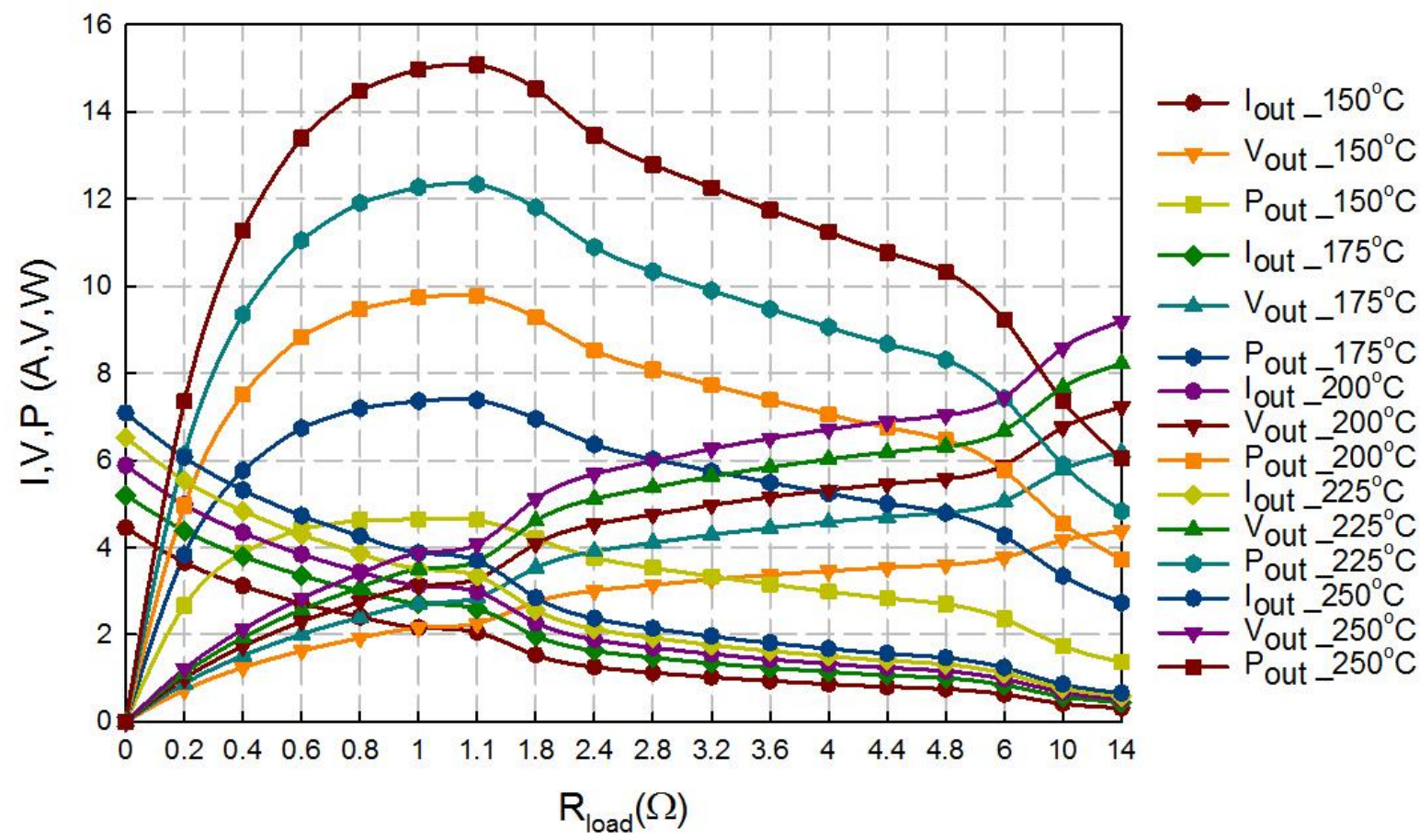

Fig. 8. Variations of output power, voltage and current at different hot side temperature with load resistance

\section{1.2 Converter parameters with direct PWM signal}

During the direct PWM mode the model is subjected to varying loads in the range of 0-40 $\Omega$ in order to find out the effect of different loads on the converter parameters at different duty cycle. Fig. 9 shows the output voltages of the converter at different temperature and duty cycle D. As observed, higher output voltage is obtained at $\mathrm{D}=10 \%$ and the least voltage is obtained at $\mathrm{D}=80 \%$. During simulation, it is noticed that different ranges of $\mathrm{D}$ gives different output voltages as indicated in Fig. 9. The maximum voltage is achieved at duty cycle range of $1-$ 20\%. Similarly the output power for the converter is shown in Fig. 10. The only observable difference between the output voltage and output power is that the rate of increase of output power with $T_{h}$ rises as $D$ increases. Nevertheless in both cases the output voltage and power increase linearly with temperature. The slopes for lines indicated in Fig. 10 are different from each other whereby the highest slope is obtained at a duty cycle range of 1-20\%. Similar trends have been recorded at other converter loads. 


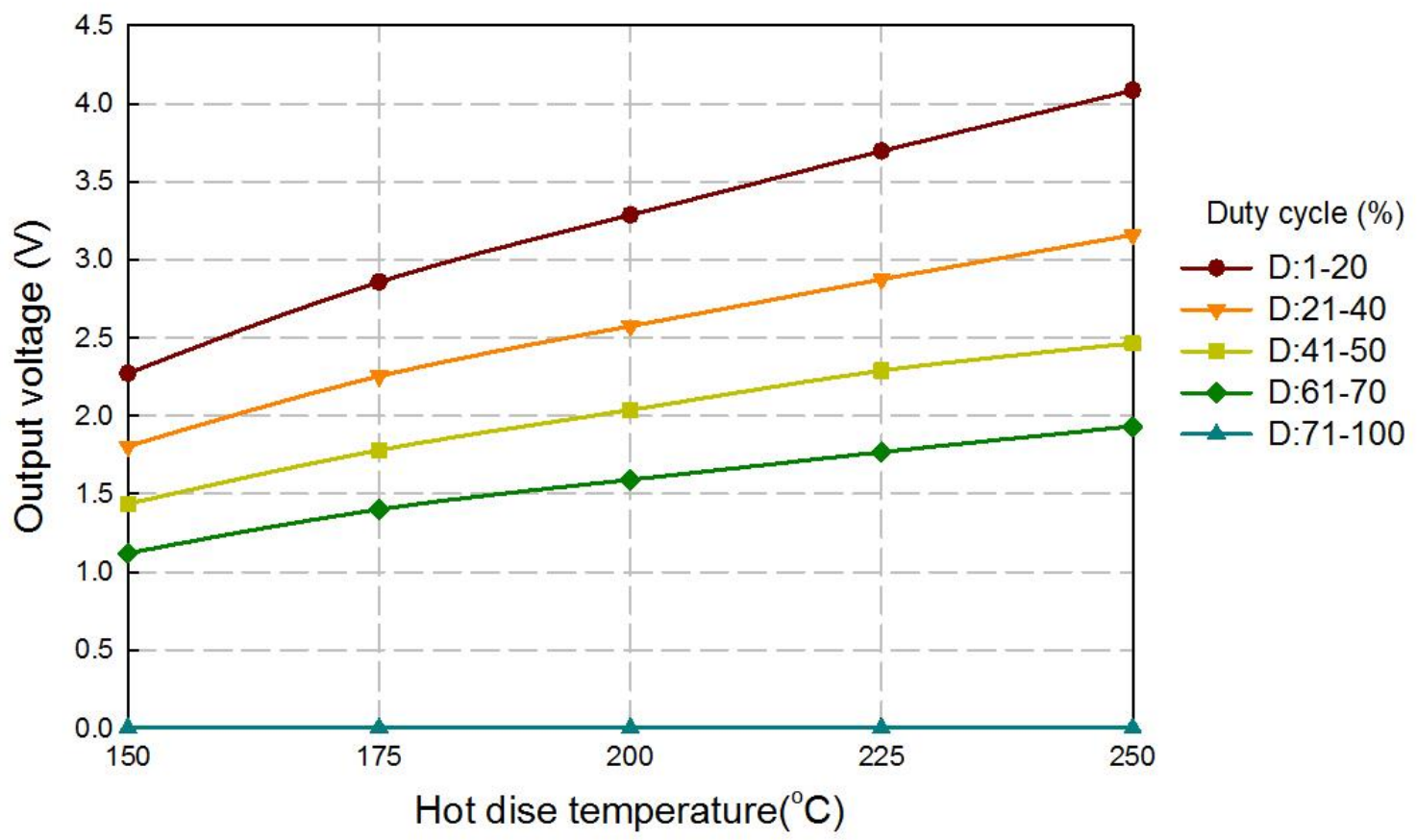

331

332 333

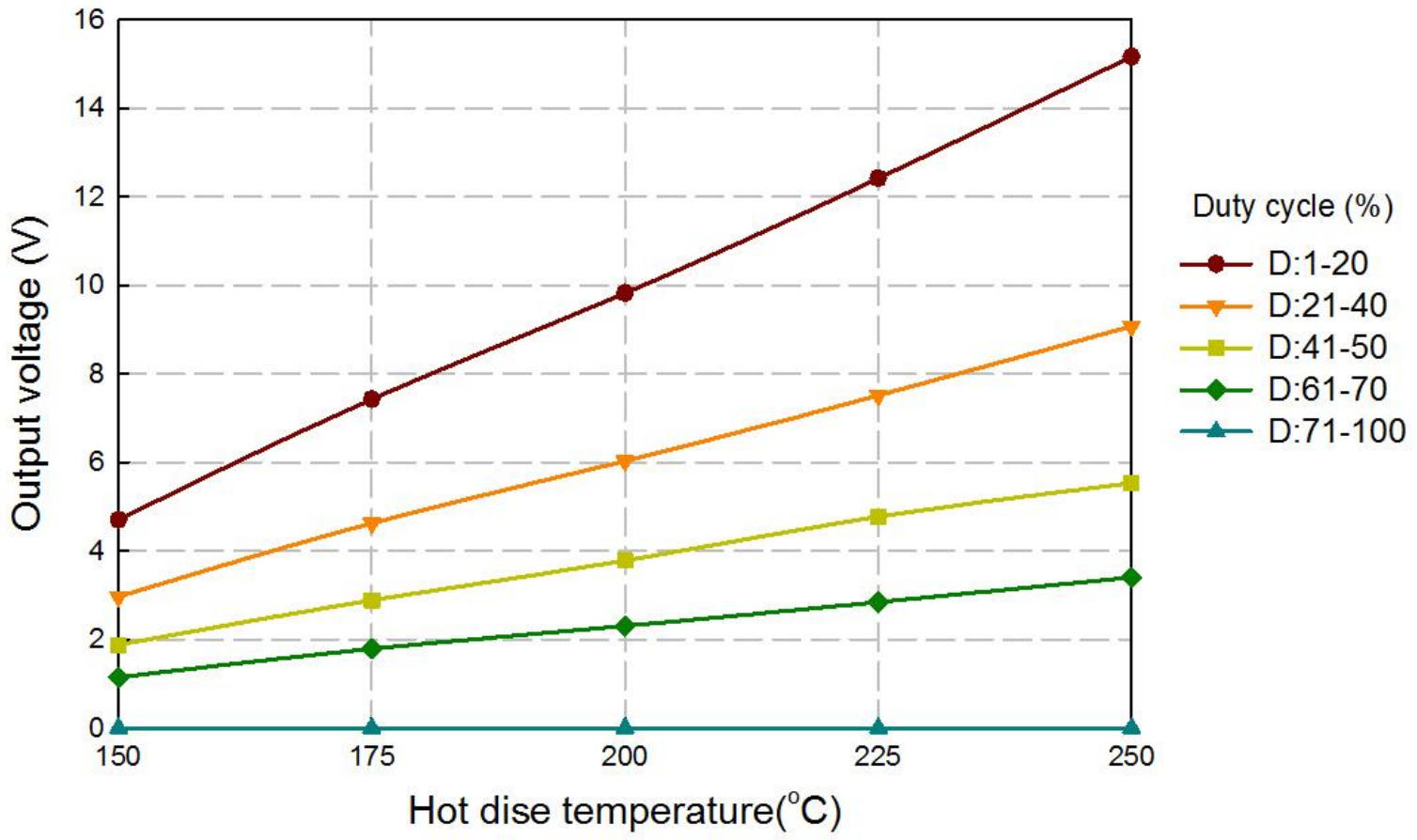

Fig. 9. Variation of converter output voltage with hot side temperature and duty cycle at $\mathrm{R}_{\text {load }}$ $=1.1 \Omega$

Fig. 10. Variation of converter output power with hot side temperature and duty cycle at $\mathrm{R}_{\text {load }}$ $=1.1 \Omega$ 
Fig. 11 shows the output power at different values of $\mathrm{D}$. For clarify, only three $\mathrm{T}_{\mathrm{h}}$ and duty cycle values have been plotted. It is noted that for the same range of duty cycle, the matching load is the same even for different temperatures. For example in Fig. 11 the matching load is $1.1 \Omega$ for $\mathrm{T}_{\mathrm{h}}$ of $150^{\circ} \mathrm{C}, 200^{\circ} \mathrm{C}$ and $250^{\circ} \mathrm{C}$ at a duty cycle of $10 \%$. However, as soon as $\mathrm{D}$ is changed, the matching load also changes. For example the matching load is $1.1 \Omega, 1.8 \Omega$ and $2.4 \Omega$ for duty cycle values of $10 \%, 30 \%$ and $50 \%$ respectively at the same $\mathrm{T}_{h}=250^{\circ} \mathrm{C}$. Therefore, it can be concluded that in cases where a fixed load is connected to the converter, it is not suitable to change the duty cycle even at different values of $\mathrm{T}_{\mathrm{h}}$.

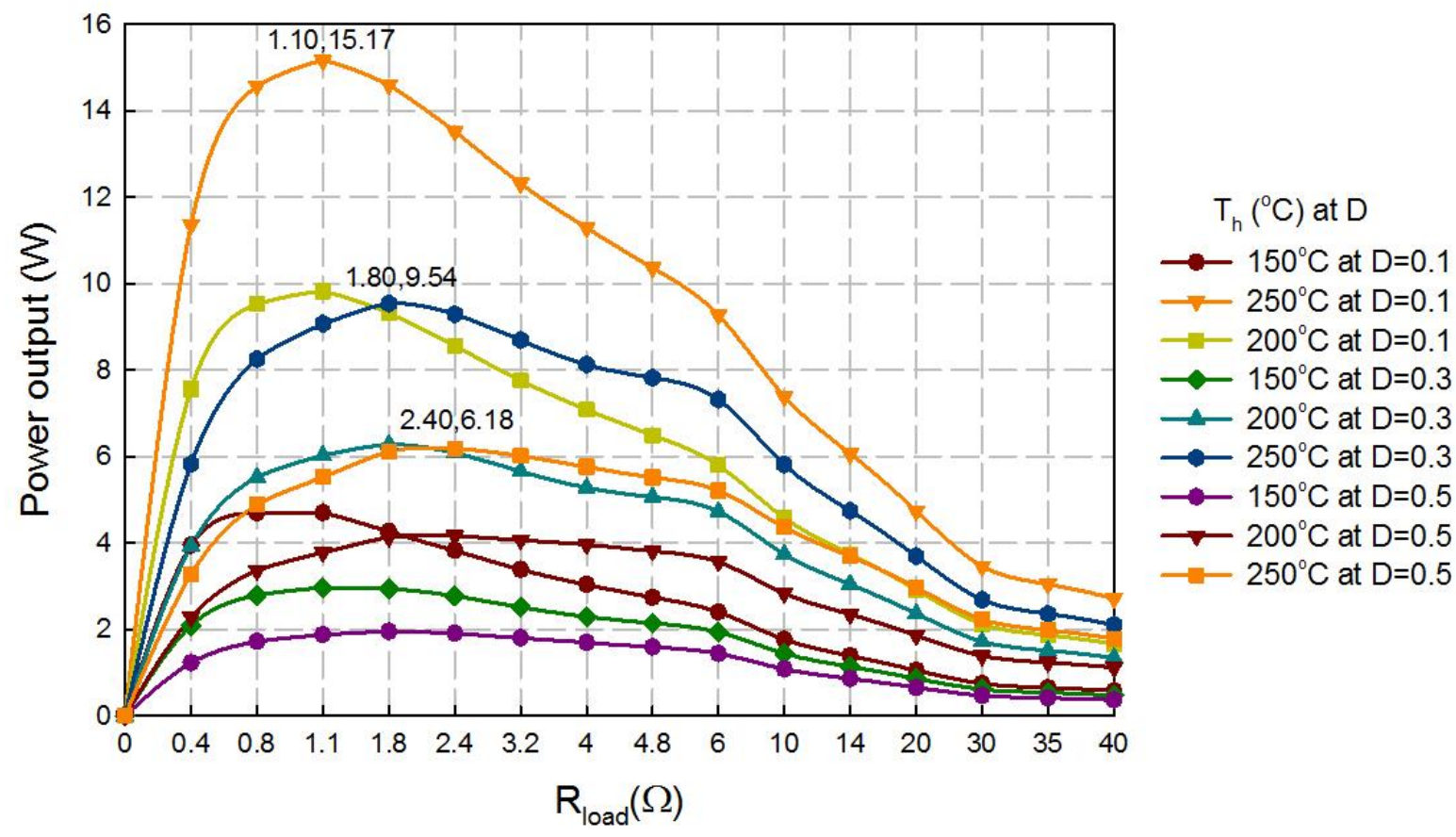

345

Fig. 11. Comparison of output power at different values of $D$ and hot side temperature

Fig. 12 shows MPPT and direct PWM model output powers. It has been observed that the maximum power from the converter is obtained at the duty cycle of $10 \%$. Also it is clear that the output power from MPPT based converter model corresponds to the output power from direct PWM mode at $\mathrm{D}=10 \%$ (as well as $\mathrm{D}$ in the range 1-20\%). However, at higher values of $\mathrm{D}$, the power output reduces. Therefore, the MPPT can automatically extract maximum power from the system without having to adjust any component from the MPPT algorithm as it is the case with direct PWM mode. 


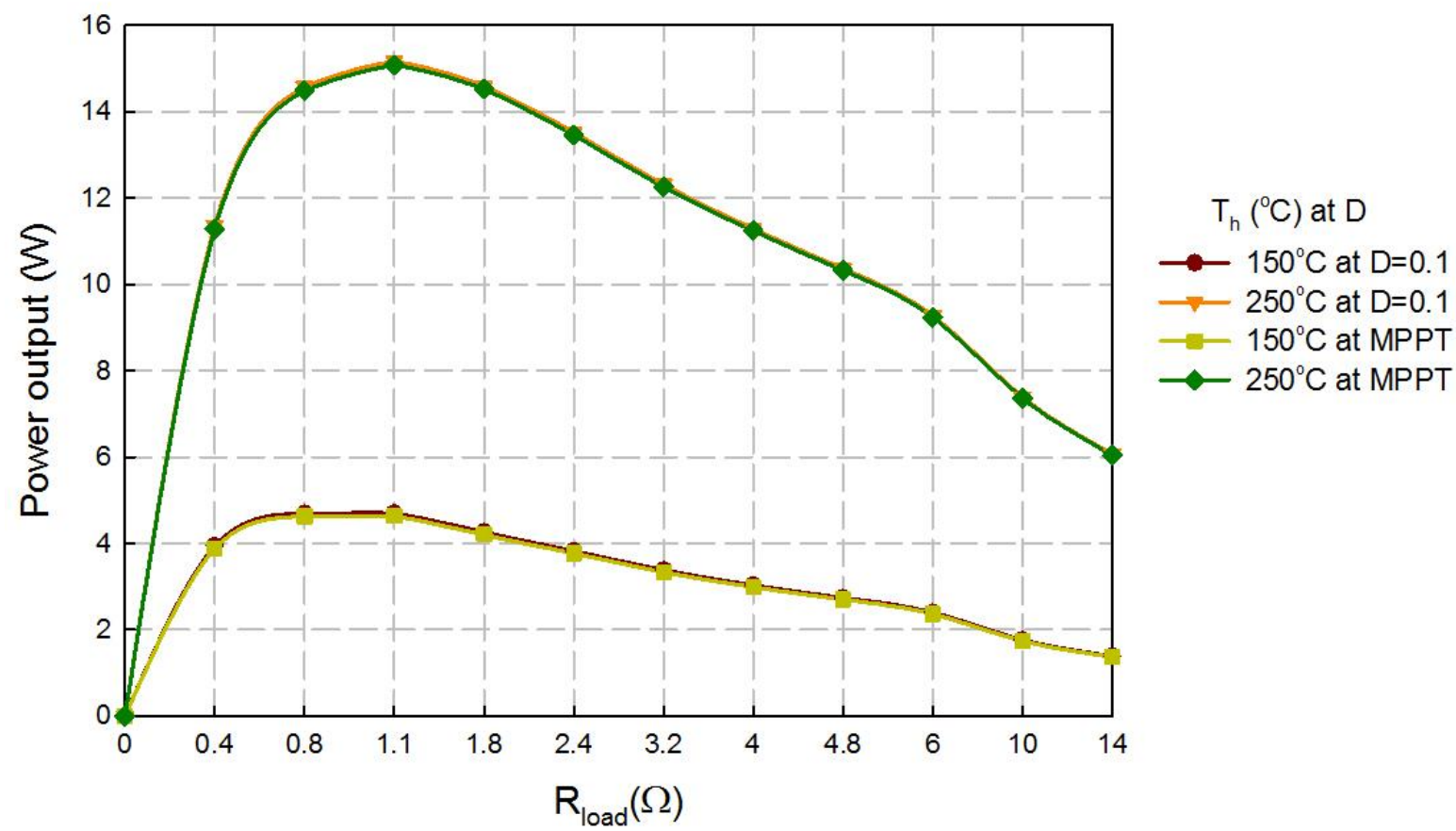

Fig. 12. Comparison between MPPT and direct PWM model output power.

Voltage conversion ratios (VCR) at $\mathrm{D}=0.1$ for different converter loads are shown in Fig. 359 13. It is clearly observed that as the temperature increases, VCR reduces. However, VCR 360 reduces with the converter load. Therefore in this TEG-dc-dc converter system, if higher 361 voltage is required it is necessary to operate the TEG system at slightly lower hot side 362 temperature so that the lower TEG output voltage can be boosted to the desired voltage level 363 suitable for the application. 


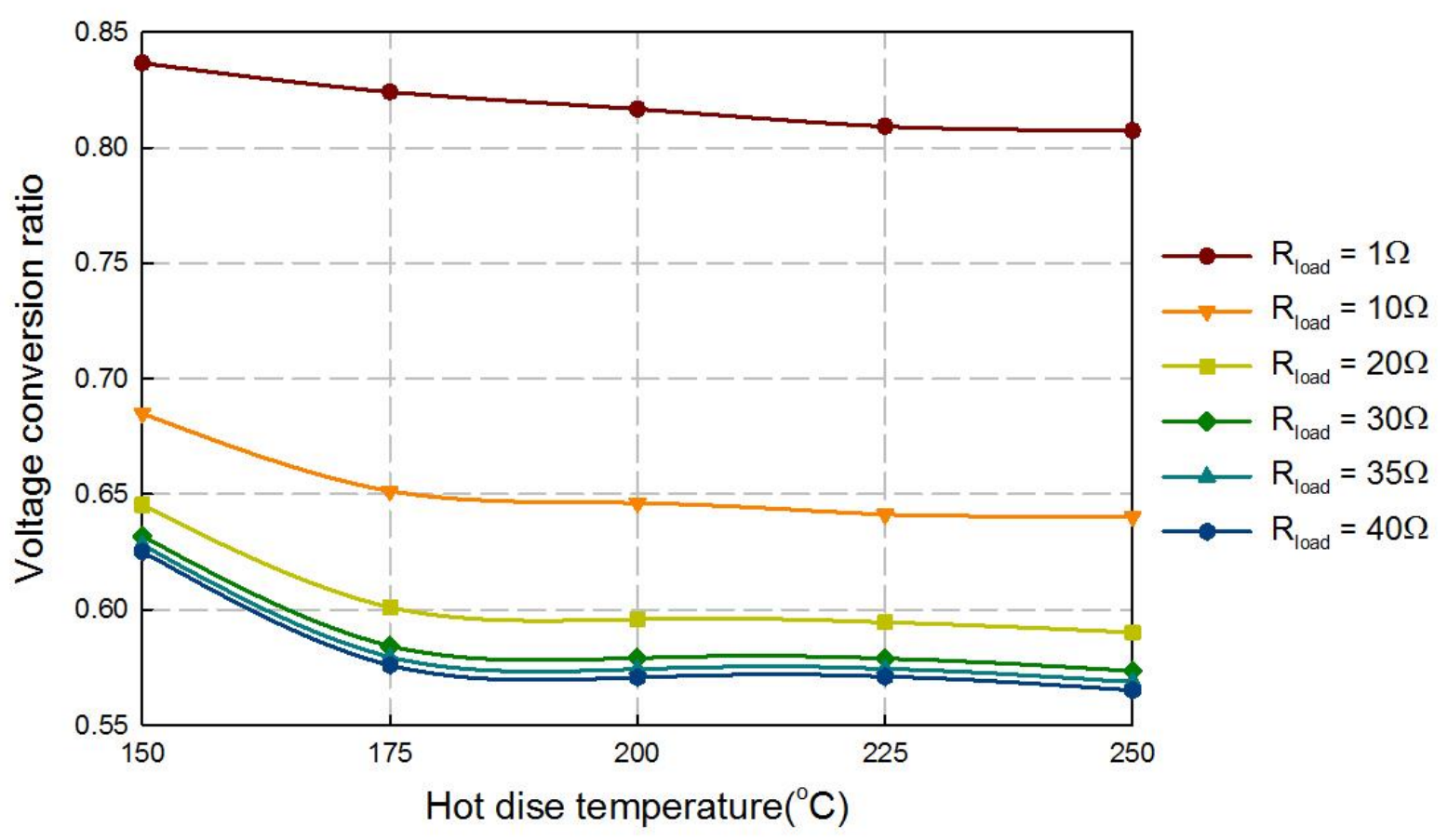

Fig. 13. Voltage conversion ratio at $\mathrm{D}=0.1$ for different converter loads

\subsection{Results for the increasing random hot side temperature}

To further study the capability of dc-dc converter to stabilise the power output from TEG, an increasing random hot side temperature in Fig. $4 \mathrm{~b}$ is applied to the MPPT and direct PWM based modes so that the behaviour of output parameters can be analysed. Note that the cold side temperature is still maintained at $30^{\circ} \mathrm{C}$. Fig. 14 shows the voltages and output current for MPPT based model with a converter load $\mathrm{R}_{\text {load }}=1.1 \Omega$. It is clearly noted from this figure that although the input temperature is random in nature, the output voltage resulting from the converter is almost constant. Unlike the input random hot side temperature at the hot side terminal, the output voltage and current have no several optimum points. Similar to the output voltage, the input voltage to the converter is almost constant because it is filtered by the input capacitor. Similarly, Fig. 15 shows the voltage and output current for MPPT based model at $\mathrm{R}_{\text {load }}=4 \Omega$. The noticeable difference is that the voltage is increased to $4.6 \mathrm{~V}$ peak for $\mathrm{R}_{\text {load }}=4 \Omega$ load as compared to $2.9 \mathrm{~V}$ peak for $\mathrm{R}_{\text {load }}=1.1 \Omega$. Additionally output current is reduced to $1.2 \mathrm{~A}$ peak down from 2.6A peak. 


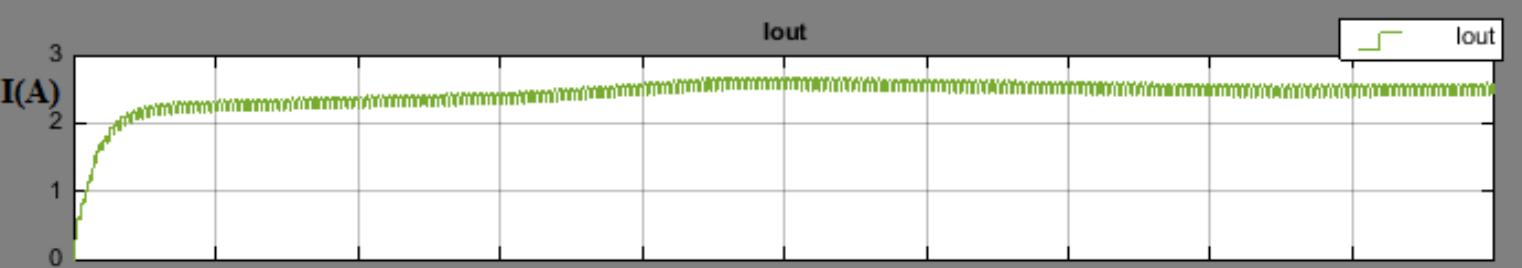

Vin
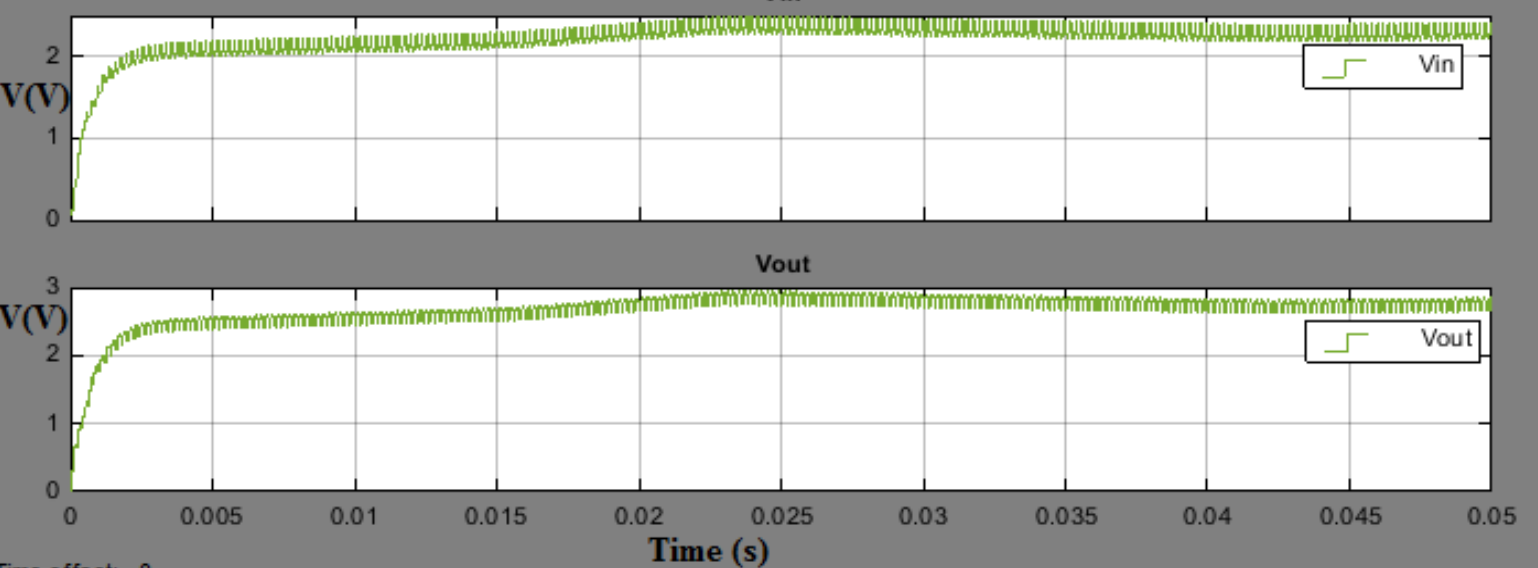

Time (s)

Fig. 14. Voltages and output current for MPPT based model with Random increasing hot side
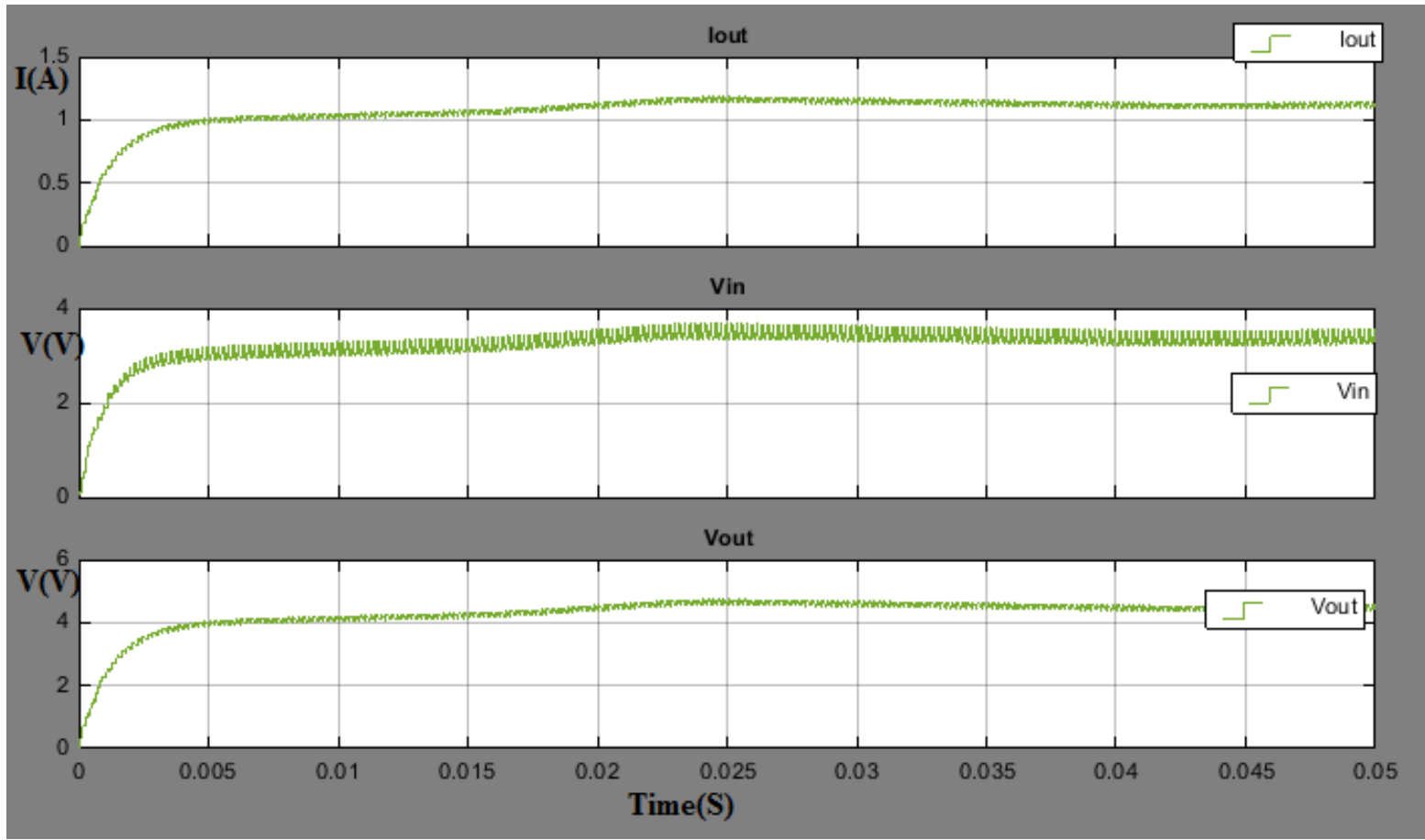

Fig. 15. Voltages and output current for MPPT based model with Random increasing hot side temperature at $\mathrm{R}_{\text {load }}=4 \Omega$

Fig. 16 shows the voltages and output current for direct PWM based model with Random increasing hot side temperature at $\mathrm{R}_{\text {load }}=1.1 \Omega$ and $\mathrm{D}=10 \%$. As already noted the output voltage 
and current are more or less the same for direct PWM mode at D $=0.1$ as that of MPPT mode.

394 The difference cannot be clearly observed on the graph but rather on calculations. Therefore, 395 similar results are indicated in Fig. 16 as those in Fig. 15 since the converter load is the same. 396 However at a higher value D i.e. $\mathrm{D}=0.5$, the converter fails to weed out some of the peaks 397 from the input voltage. Hence the input voltage as well as output voltage and current are 398 observed with over shooting behaviour in Fig. 17, which may result into more converter losses. 399 It is therefore recommended to use a converter at a lower duty cycle to get a highly stabilised 400 output power. However, the best option is to make use of MPPT algorithm since it 401 automatically choose the MPP without the need to adjust the duty cycle.

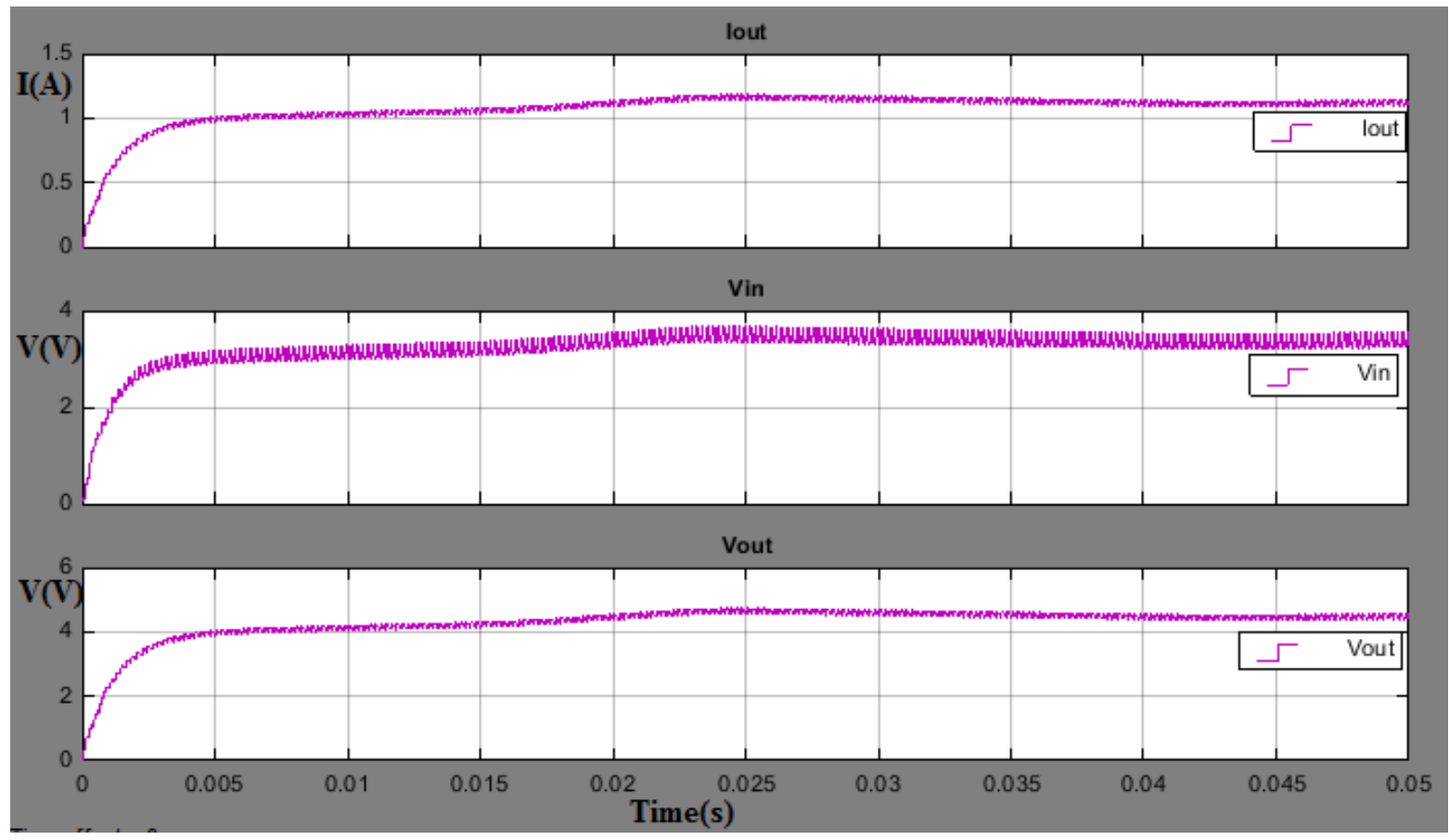

Fig. 16. Voltages and output current for direct PWM based model with Random increasing hot side temperature at $\mathrm{D}=0.1$ and $\mathrm{R}_{\text {load }}=4 \Omega$ 


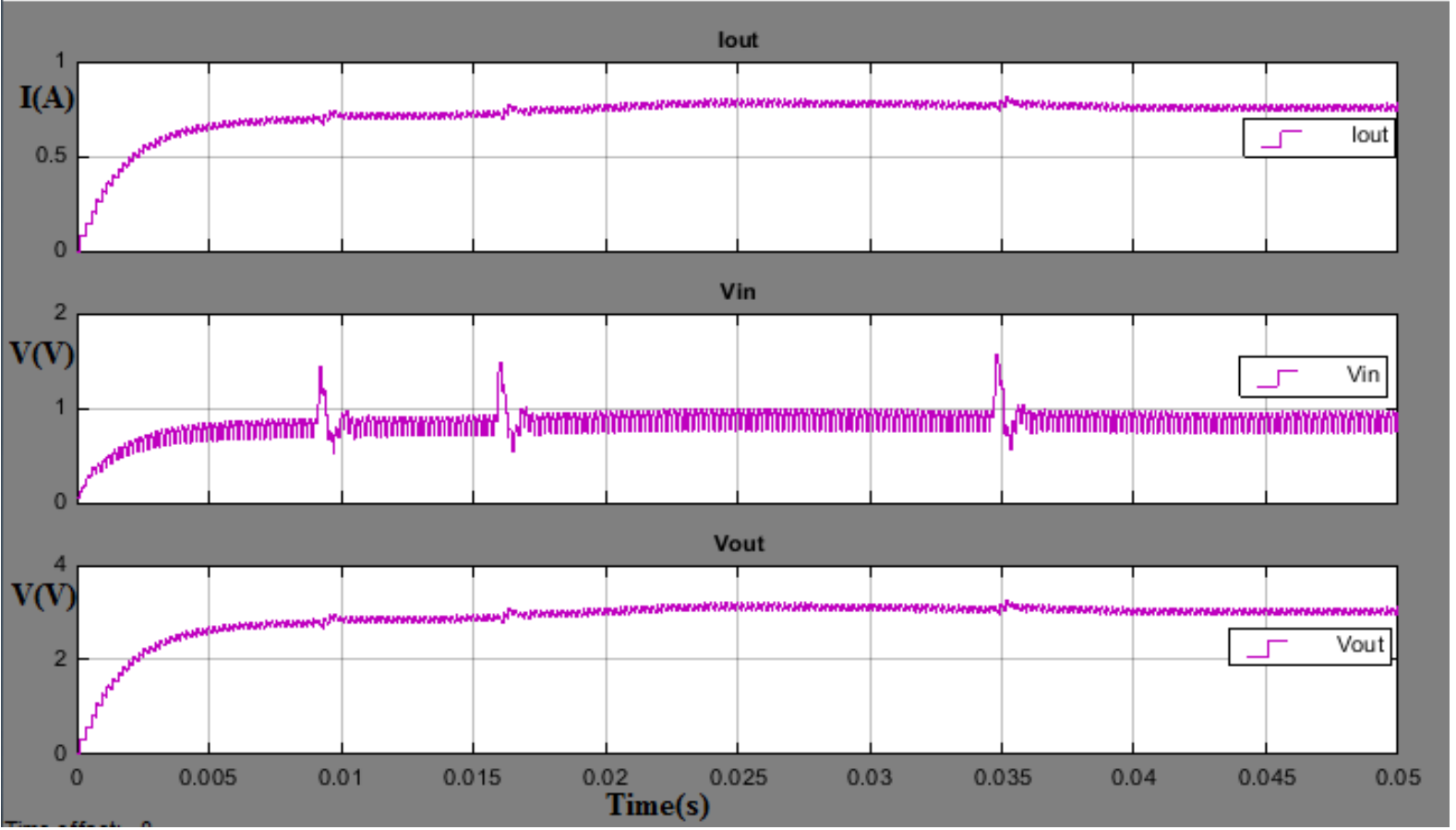

Fig. 17. Voltage and output current for direct PWM based model with Random increasing hot side temperature at $\mathrm{D}=0.5$ and $\mathrm{R}_{\text {load }}=4 \Omega$

\subsection{Effect of the converter components on the accuracy of the results}

In this section, the cause of inaccuracy in converter output parameters are discussed. As 412 discussed earlier, the converter losses are mainly caused by parasitic resistance of the converter 413 components such as the ESR of input and output capacitors, resistance of the inductor, 414 sometimes the resistance of the switch and others. Fig. 18a and 18b indicate the residual voltage 415 that remains when the converter is not loaded i.e. at $\mathrm{R}_{\text {load }}=0 \Omega$. This represents the ripple voltage 416 caused by ESR of the output capacitor since the output capacitor is in parallel with $\mathrm{R}_{\text {load. }} \mathrm{In}$ 417 Fig. 18a the ESR is kept at $1 \times 10^{-9} \Omega$ while in Fig. $18 \mathrm{~b}$ it is $1 \times 10^{-6} \Omega$. The voltage spikes on the 418 ripple can be observed to increase when the ESR is increase from $1 \mathrm{e}-9 \Omega$ to $1 \times 10^{-6} \Omega$ in Fig. $18 \mathrm{~b}$. 

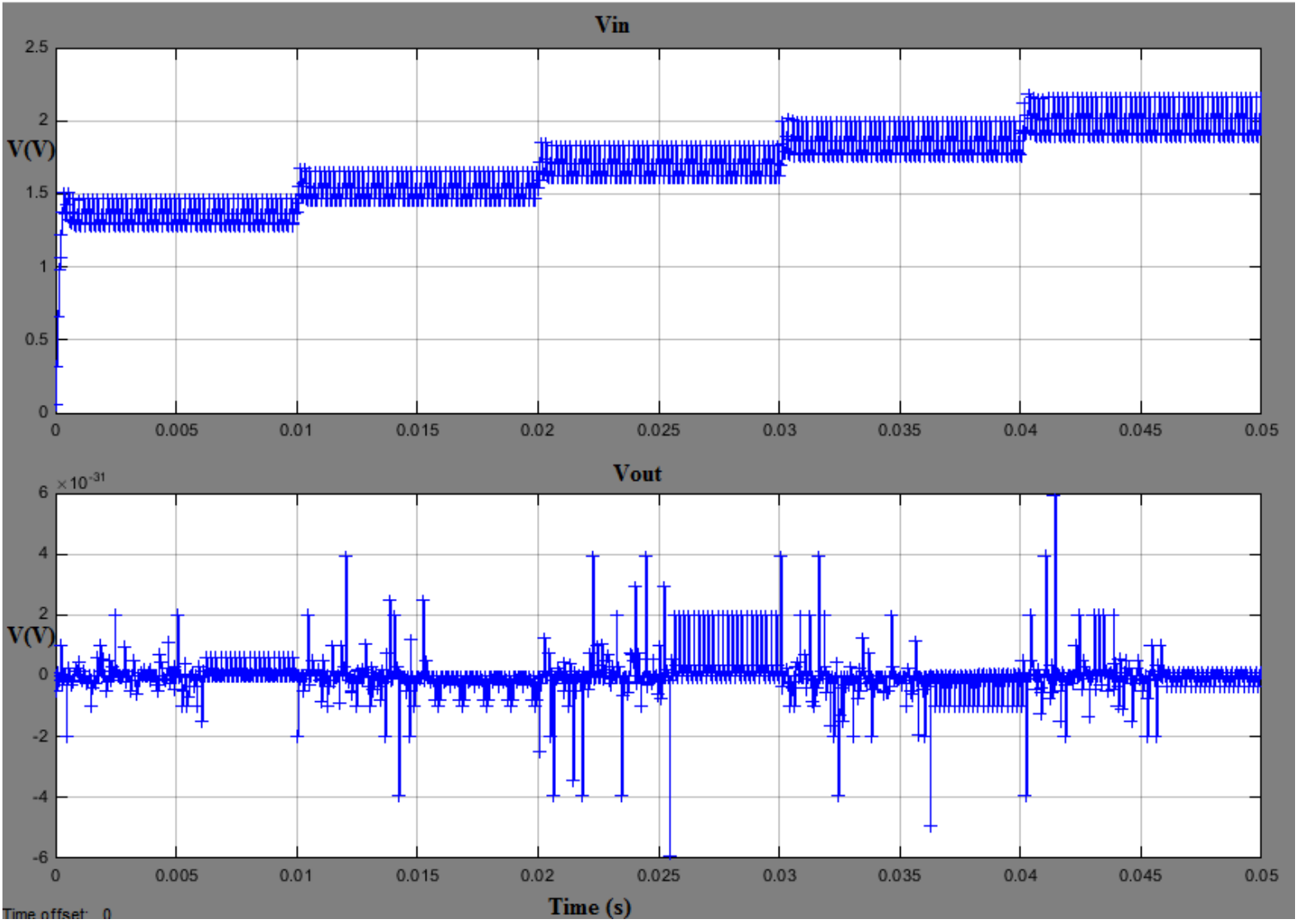

Fig. 18a. Ripple voltage at $\mathrm{ESR}=1 \times 10^{-9} \Omega$

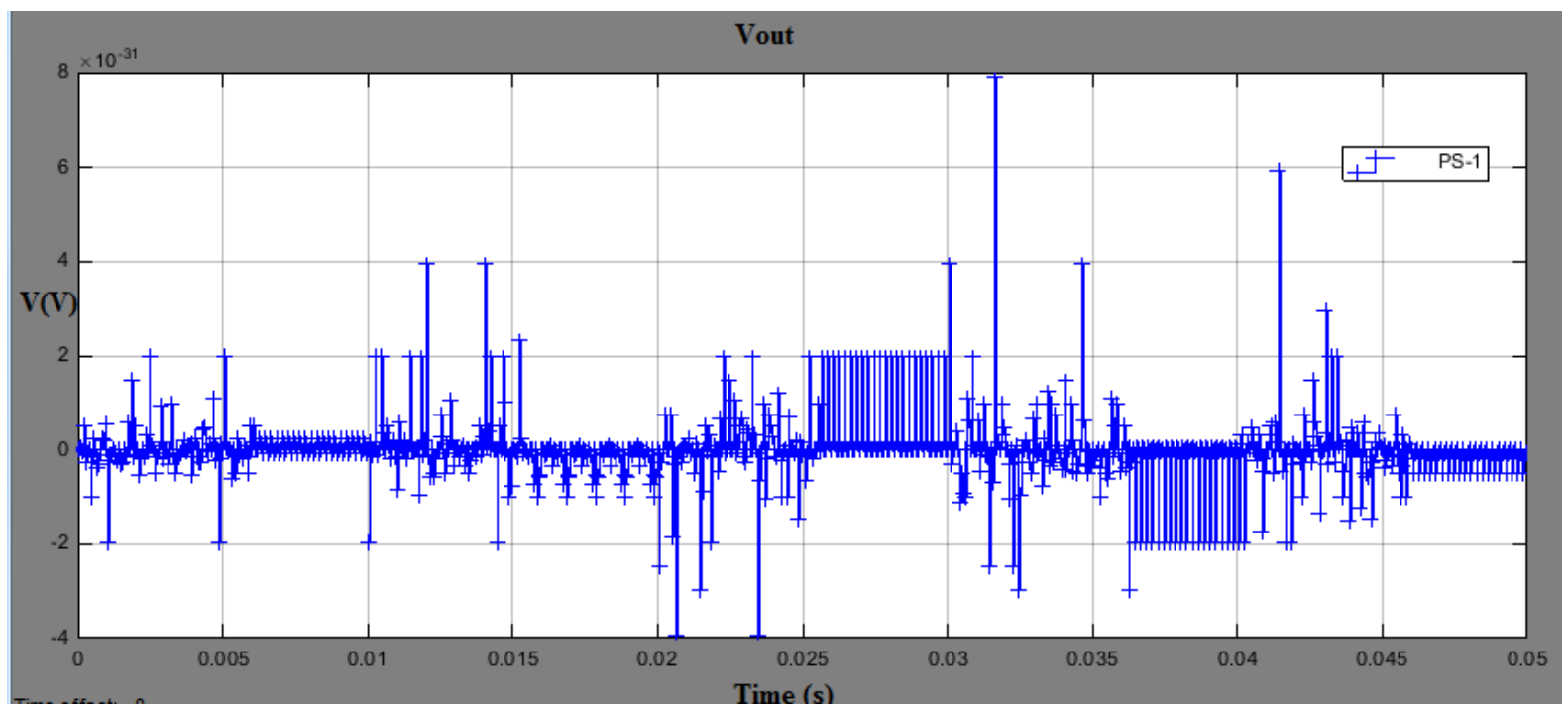

Fig. 18b. Ripple voltage at $\mathrm{ESR}=1 \times 10^{-6} \Omega$

The effect of ripple voltage can clearly be noticed if the load is increased from $0 \Omega$ to $1 \Omega$.

426 Fig. 19a and $19 \mathrm{~b}$ show the ripple voltage for ESR of $1 \times 10^{-6} \Omega$ and $1 \Omega$ respectively at $\mathrm{R}_{\text {load }}=$ $4271 \Omega$. In Fig. 19a, the spread of the ripple voltage on the output voltage is less than that of ESR of $1 \Omega$. Since the ripples are higher frequency harmonics and are within the audible range, if 
429

430

431

432

433

434

435

436

437

438

439

440

441

442

443

444

445

the converter load is an audio equipment such as radio receiver, the ripple will be audible within the output of the receiver and therefore cause noise interference. Therefore, the ESR has to be reduced as low as possible, else the ripple should be filtered to avoid such unnecessary occurrences within the TEG system.

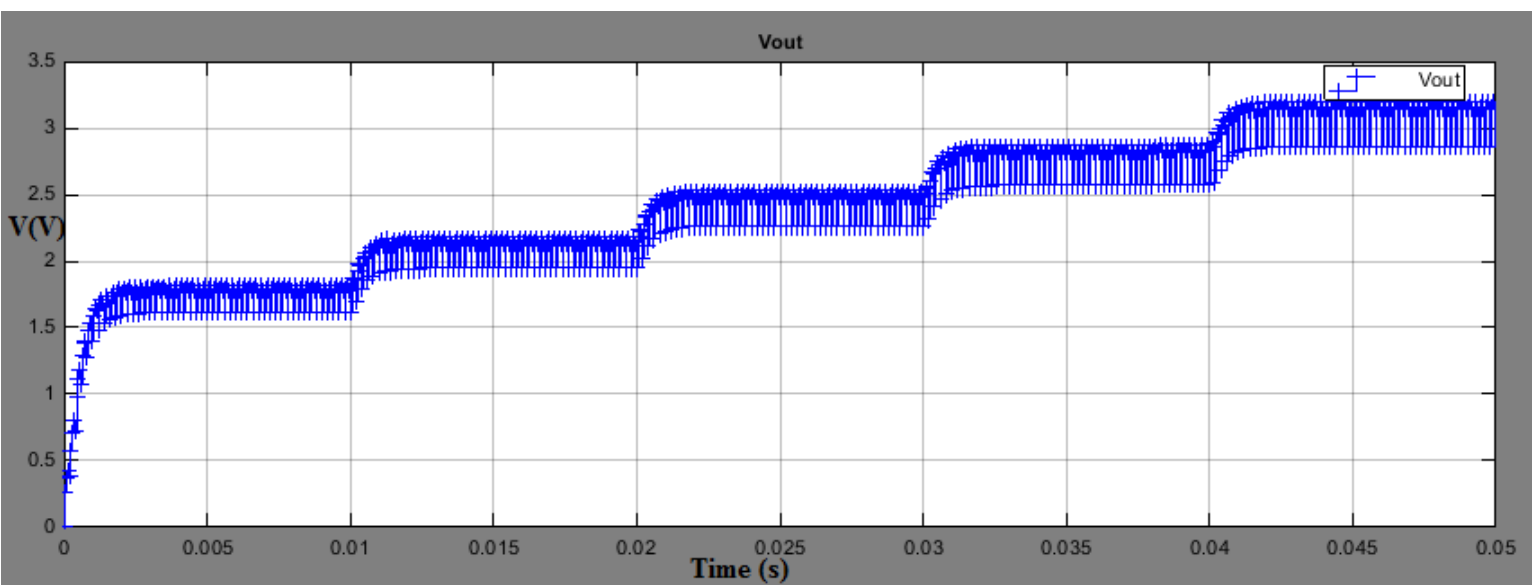

Fig. 19a. Ripple voltage at $\mathrm{ESR}=1 \times 10^{-6} \Omega$ when $\mathrm{R}_{\text {load }}=1 \Omega$

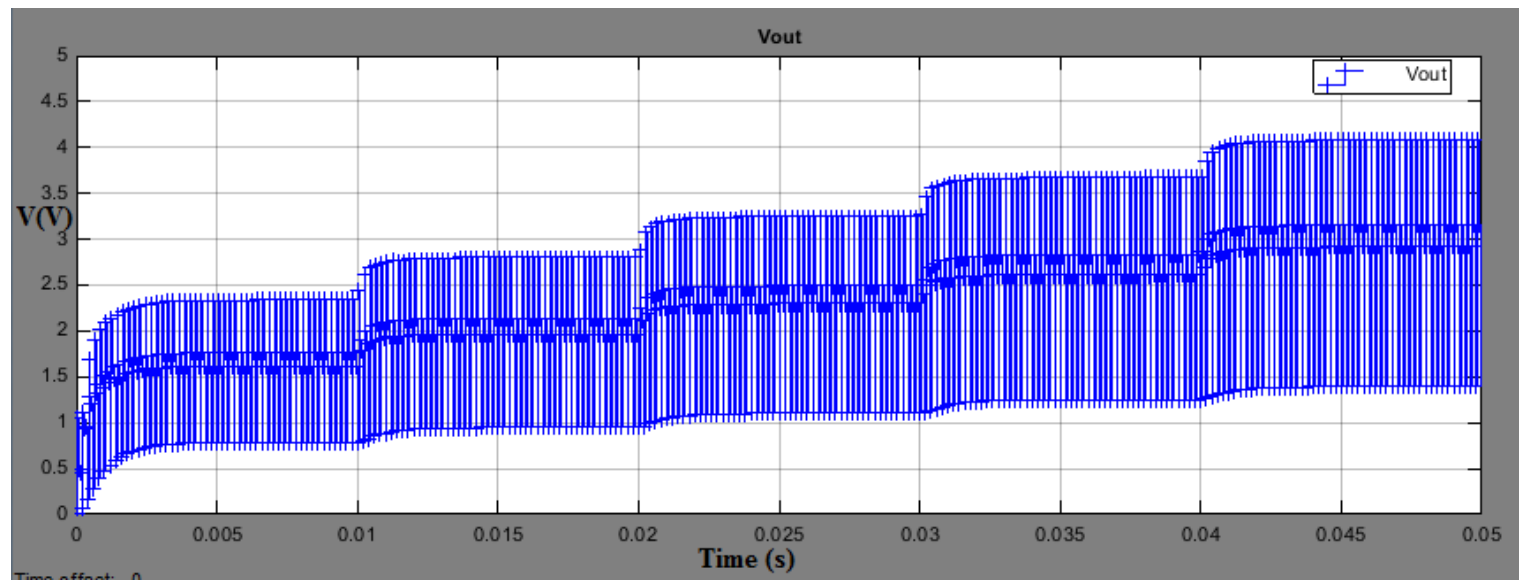

Fig. 19b. Ripple voltage at $\mathrm{ESR}=1 \Omega$ when $\mathrm{R}_{\text {load }}=1 \Omega$

The switching frequency also needs proper tuning as it affects the output parameters. Fig. 20 illustrates the effect of increasing the switching frequency from $5 \mathrm{kHz}$ to $20 \mathrm{kHz}$ on the input and output voltages with overshooting. Although increasing $\mathrm{F}_{\mathrm{sw}}$ reduces inductor ripple current and output ripple voltage, it has the disadvantage of increasing the switching losses, hence reducing efficiency. 

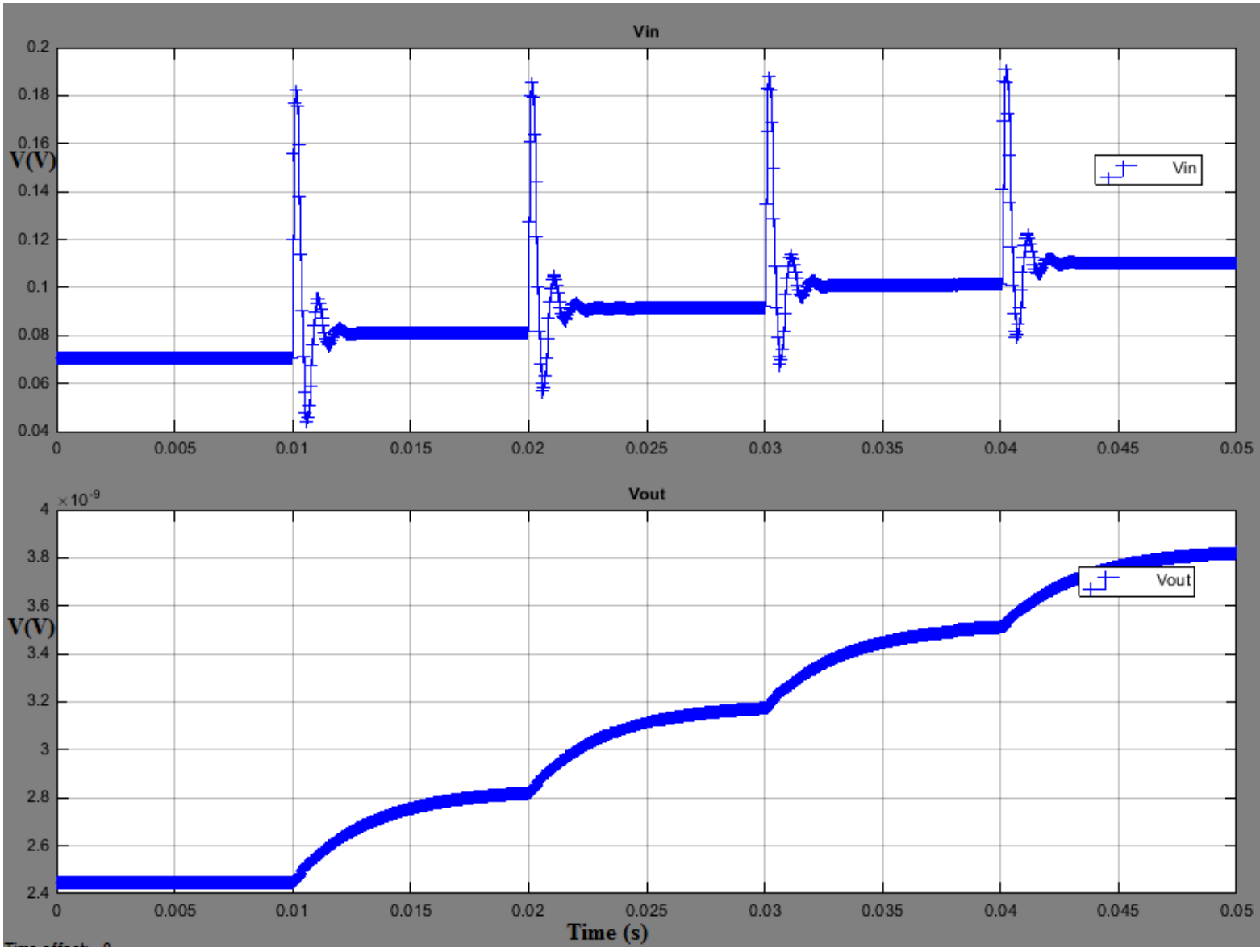

Fig. 20. Effect of increasing the switching frequency from $5 \mathrm{kHz}$ to $20 \mathrm{kHz}$ on the input and

$$
\text { output voltages }
$$

449

450

451

452

453

454

455

456

457

458

459

460

461

462

\section{Conclusion}

A dc-dc converter as a power conditioning device can provide a more stable power output and facilitate the extraction of more power from the TEG system. But, for performance improvement, maximum power point tracking (MPPT) algorithm can be applied to extract the maximum power from TEG system. Therefore, this work has analysed the performance of a TEG/dc-dc converter system and the parameters that influence the system's performance in different modes. A TEG/dc-dc boost converter model has been investigated in both MPPT and direct pulse width modulation (PWM) modes subjected to a variable load. To further study the ability of dc-dc converters to stabilise the power output from TEG system, increasing ramp and random hot side temperature profiles have been applied to the MPPT and direct PWM based modes so that the effect on output parameters i.e. voltage and power, are analysed. It has been noted that even for the random temperature input to the TEG, the output voltage resulting from the converter is almost constant. Therefore dc-dc converters are able to stabilise the power generated from TEG. It has also been observed that dc-dc converter with MPPT based model 
is able to effectively extract maximum power from TEG compared to the direct PWM based model. It has been established that for maximum power to be achieved easily, an optimum load has to be connected to the system. Besides, proper selection of converter components is necessary to avoid converter losses as well noise interferences on the load connected to TEG/dc-dc converter system.

\section{References}

[1] X. Liu, C. Li, Y. D. Deng, and C. Q. Su, “An energy-harvesting system using thermoelectric power generation for automotive application," Int. J. Electr. Power Energy Syst., vol. 67, pp. 510-516, 2015.

[2] M. Noori, S. Gardner, and O. Tatari, "Electric vehicle cost, emissions, and water footprint in the United States: Development of a regional optimization model," Energy, vol. 89, pp. 610-625, 2015.

[3] K. Ebrahimi, G. F. Jones, and A. S. Fleischer, "A review of data center cooling technology, operating conditions and the corresponding low-grade waste heat recovery opportunities," Renew. Sustain. Energy Rev., vol. 31, pp. 622-638, 2014.

[4] T. Seetawan, K. Singsoog, and S. Srichai, "Thermoelectric Energy Conversion of pCa3Co4O9/n-CaMnO3 Module," in The 6th International Conference on Applied Energy - ICAE2014, 2014, vol. 0, pp. 2-5.

[5] S. Twaha, J. Zhu, Y. Yan, and B. Li, "A comprehensive review of thermoelectric technology: Materials, applications, modelling and performance improvement," Renew. Sustain. Energy Rev., vol. 65, pp. 698-726, 2016.

[6] M. M. Barry, K. A. Agbim, and M. K. Chyu, "Performance of a Thermoelectric Device with Integrated Heat Exchangers," J. Electron. Mater., vol. 44, no. 6, pp. 1394-1401, 2015.

[7] S. Leblanc, "Sustainable Materials and Technologies Thermoelectric generators : Linking material properties and systems engineering for waste heat recovery applications," Susmat, vol. 1-2, pp. 26-35, 2014.

[8] J. Gao, Q. Du, M. Chen, B. Li, and D. Zhang, "Assessing the accuracy of mathematical models used in thermoelectric simulation: Thermal influence of insulated air zone and radiation heat," Appl. Therm. Eng., vol. 82, pp. 162-169, 2015.

[9] U. Erturun and K. Mossi, "Thermoelectric devices with rotated and coaxial leg configurations: Numerical analysis of performance," Appl. Therm. Eng., vol. 85, pp. 304-312, 2015.

[10] U. Erturun, K. Erermis, and K. Mossi, "Effect of various leg geometries on thermomechanical and power generation performance of thermoelectric devices," Appl. Therm. Eng., vol. 73, no. 1, pp. 126-139, 2014.

[11] Y. Y. HUANG KUO, BO LI, SSENNOGA TWAHA, "Comprehensive Study on Novel Concentric Cylindrical Thermoelectric Power Generation System," Appl. Therm. Eng., 2016.

[12] M. A. M. Ramli, S. Twaha, K. Ishaque, and Y. A. Al-Turki, "A review on maximum power point tracking for photovoltaic systems with and without shading conditions," Renew. Sustain. Energy Rev., vol. 67, pp. 144-159, 2016. 
[13] A. M. Yusop, R. Mohamed, and A. Mohamed, "Inverse dynamic analysis type of MPPT control strategy in a thermoelectric-solar hybrid energy harvesting system," Renew. Energy, vol. 86, pp. 682-692, 2016.

[14] A. Paraskevas and E. Koutroulis, "A simple maximum power point tracker for thermoelectric generators," Energy Convers. Manag., vol. 108, pp. 355-365, 2016.

[15] M. G. Molina, L. E. Juanicó, G. F. Rinalde, E. Taglialavore, and S. Gortari, "Design of improved controller for thermoelectric generator used in distributed generation," Int. J. Hydrogen Energy, vol. 35, no. 11, pp. 5968-5973, 2010.

[16] Y. H. Liu, Y. H. Chiu, J. W. Huang, and S. C. Wang, "A novel maximum power point tracker for thermoelectric generation system," Renew. Energy, vol. 97, pp. 306-318, 2016.

[17] Y. H. Liu, Y. H. Chiu, J. W. Huang, S. C. Wang, S. Manikandan, S. C. Kaushik, M. G. Molina, L. E. Juanicó, G. F. Rinalde, A. Paraskevas, E. Koutroulis, C. Yu, K. T. Chau, A. M. Yusop, R. Mohamed, A. Mohamed, X. Zhang, and K. T. Chau, "Thermodynamic studies and maximum power point tracking in thermoelectric generator-thermoelectric cooler combined system," Energy Convers. Manag., vol. 97, no. 13, pp. 682-692, 2016.

[18] M. G. Molina, L. E. Juanicó, and G. F. Rinalde, "Design of innovative power conditioning system for the grid integration of thermoelectric generators," Int. J. Hydrogen Energy, vol. 37, no. 13, pp. 10057-10063, 2012.

[19] S. Twaha, J. Zhu, Y. Yan, B. Li, and K. Huang, "Performance analysis of thermoelectric generator using dc-dc converter with incremental conductance based maximum power point tracking," Energy Sustain. Dev., 2017.

[20] S. Yu, Q. Du, H. Diao, G. Shu, and K. Jiao, "Start-up modes of thermoelectric generator based on vehicle exhaust waste heat recovery," Appl. Energy, vol. 138, pp. 276-290, 2015.

[21] X. F. Zheng, C. X. Liu, Y. Y. Yan, and Q. Wang, "A review of thermoelectrics research - Recent developments and potentials for sustainable and renewable energy applications," Renew. Sustain. Energy Rev., vol. 32, pp. 486-503, 2014.

[22] Y. S. H. Najjar and M. M. Kseibi, "Heat Transfer and Performance Analysis of Thermoelectric Stoves," Appl. Therm. Eng., vol. 102, pp. 1045-1058, 2016.

[23] Z. Niu, S. Yu, H. Diao, Q. Li, K. Jiao, Q. Du, H. Tian, and G. Shu, "Elucidating modeling aspects of thermoelectric generator," Int. J. Heat Mass Transf., vol. 85, pp. 12-32, 2015.

[24] S. Twaha, J. Zhu, Y. Yan, and B. Li, “A comprehensive review of thermoelectric technology: Materials, applications, modelling and performance improvement," Renew. Sustain. Energy Rev., vol. 65, 2016.

[25] S. Lv, W. He, L. Wang, G. Li, J. Ji, H. Chen, and G. Zhang, "Design, fabrication and feasibility analysis of a thermo-electric wearable helmet," Appl. Therm. Eng., vol. 109, pp. 138-146, 2016.

[26] M. Li, "Thermoelectric-Generator-Based DC-DC Conversion Network for Automotive Applications," KTH Information and Communication Technology, 2011.

[27] S. Twaha, J. Zhu, and Y. Yan, "Power conditioning of thermoelectric generated power using dc-dc converters: a case study of a boost converter," in International Heat Transfer Symposium 2016, 2016.

[28] K. Uddin, A. D. Moore, A. Barai, and J. Marco, "The effects of high frequency current ripple on electric vehicle battery performance," Appl. Energy, vol. 178, pp. 142-154, 2016.

[29] M. Büyük, A. Tan, M. Tümay, and K. Ç. Bayindir, "Topologies, generalized designs, passive and active damping methods of switching ripple filters for voltage source 
inverter: A comprehensive review," Renew. Sustain. Energy Rev., vol. 62, pp. 46-69, 2016.

[30] R. Mikkenie, O. Steigelmann, W. A. Groen, and J. E. Ten Elshof, "A quick method to determine the capacitance characteristics of thin layer X5R multilayer capacitors," $J$. Eur. Ceram. Soc., vol. 32, no. 1, pp. 167-173, 2012.

[31] K. Ishaque, Z. Salam, and G. Lauss, "The performance of perturb and observe and incremental conductance maximum power point tracking method under dynamic weather conditions," Appl. Energy, vol. 119, pp. 228-236, 2014.

[32] C. Yu and K. T. Chau, "Thermoelectric automotive waste heat energy recovery using maximum power point tracking," Energy Convers. Manag., vol. 50, no. 6, pp. 1506$1512,2009$. 